University of New Hampshire

University of New Hampshire Scholars' Repository

Doctoral Dissertations

Student Scholarship

Spring 2003

\title{
Spatial properties of photophobia
}

James Michael Stringham

University of New Hampshire, Durham

Follow this and additional works at: https://scholars.unh.edu/dissertation

\section{Recommended Citation}

Stringham, James Michael, "Spatial properties of photophobia" (2003). Doctoral Dissertations. 172.

https://scholars.unh.edu/dissertation/172

This Dissertation is brought to you for free and open access by the Student Scholarship at University of New Hampshire Scholars' Repository. It has been accepted for inclusion in Doctoral Dissertations by an authorized administrator of University of New Hampshire Scholars' Repository. For more information, please contact Scholarly.Communication@unh.edu. 


\section{INFORMATION TO USERS}

This manuscript has been reproduced from the microfilm master. UMI films the text directly from the original or copy submitted. Thus, some thesis and dissertation copies are in typewriter face, while others may be from any type of computer printer.

The quality of this reproduction is dependent upon the quality of the copy submitted. Broken or indistinct print, colored or poor quality illustrations and photographs, print bleedthrough, substandard margins, and improper alignment can adversely affect reproduction.

In the unlikely event that the author did not send UMI a complete manuscript and there are missing pages, these will be noted. Also, if unauthorized copyright material had to be removed, a note will indicate the deletion.

Oversize materials (e.g., maps, drawings, charts) are reproduced by sectioning the original, beginning at the upper left-hand corner and continuing from left to right in equal sections with small overlaps.

ProQuest Information and Leaming 300 North Zeeb Road, Ann Arbor, MI 48106-1346 USA 800-521-0600

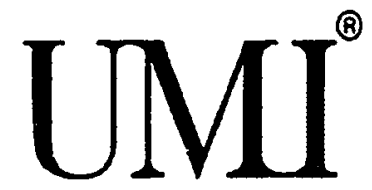


SPATIAL PROPERTIES OF PHOTOPHOBIA

\section{BY}

\section{JAMES M. STRINGHAM}

B.S. Arizona State University, 1997

M.A. University of New Hampshire, 2000

\section{DISSERTATION}

Submitted to the University of New Hampshire in Partial Fulfillment of the Requirements for the Degree of

\section{Doctor of Philosophy}

In

Psychology

May, 2003 
UMI Number: 3083743

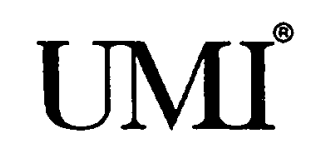

UMI Microform 3083743

Copyright 2003 by ProQuest Information and Learning Company.

All rights reserved. This microform edition is protected against unauthorized copying under Title 17, United States Code.

ProQuest Information and Learning Company

300 North Zeeb Road

P.O. Box 1346

Ann Arbor, MI 48106-1346 
This dissertation has been examined and approved.
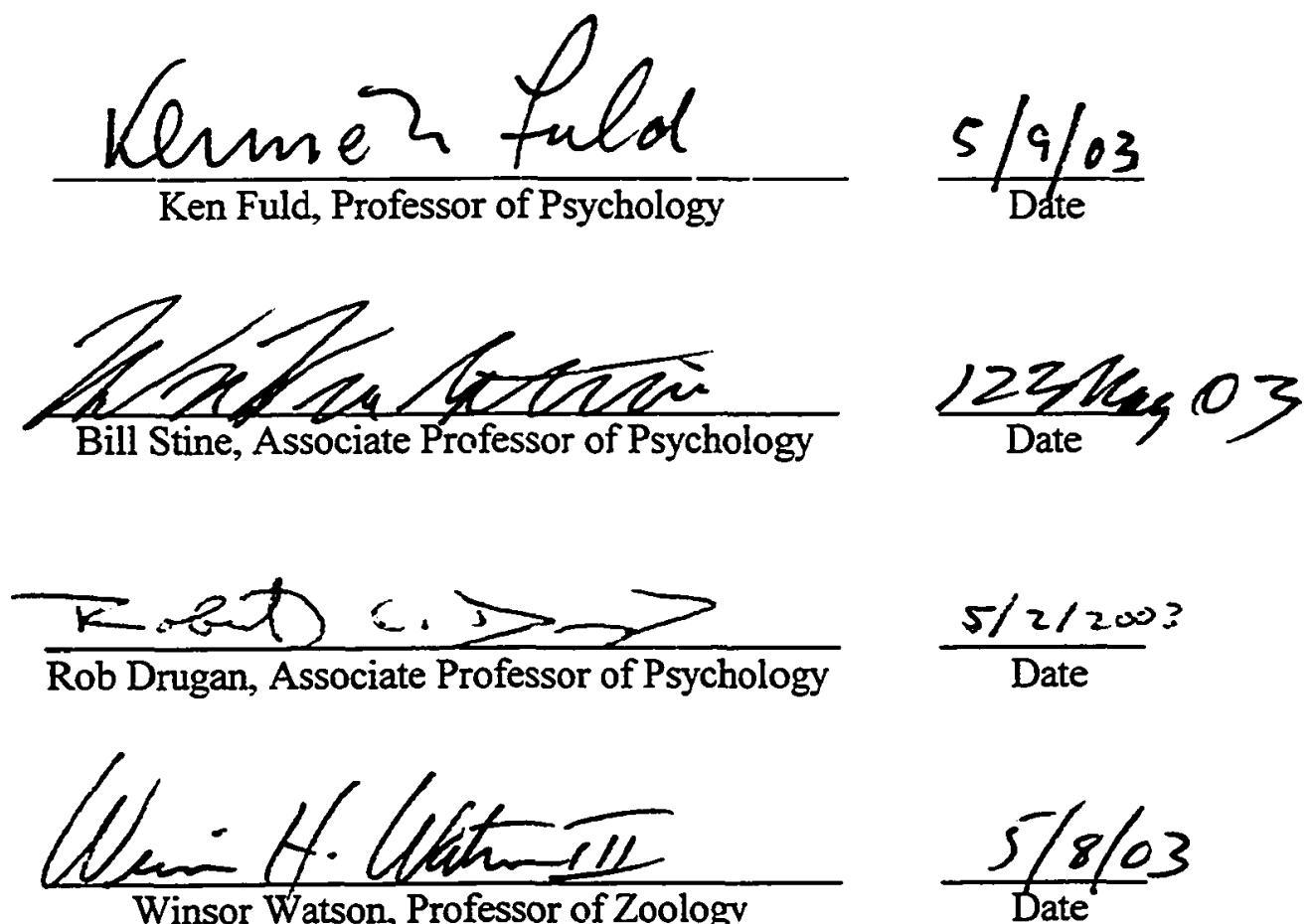

$\frac{5 / 2 / 200 ?}{\text { Date }}$

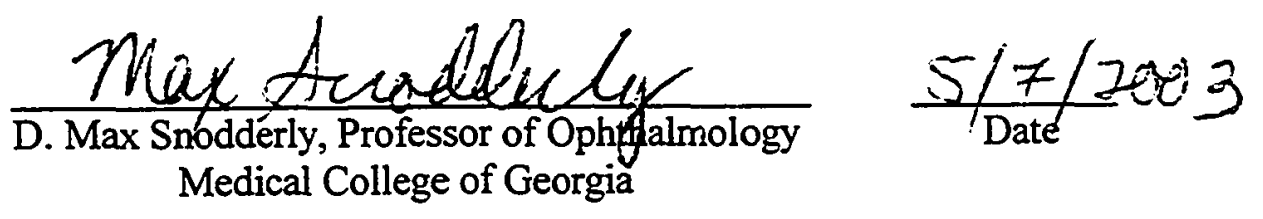




\section{ACKNOWLEDGEMENTS}

I wish to thank the members of my dissertation committee for their insightful guidance and helpful suggestions regarding my research project and this manuscript.

Michele Stringham and Adam Wenzel were subjects for this research, and for this I owe them both a debt of gratitude.

Lastly I thank my graduate mentor, Ken Fuld, for his subtly skillful guidance of me throughout my graduate career. He is an exemplar of professorship. 


\section{TABLE OF CONTENTS}

ACKNOWLEDGEMENTS...............................................ii

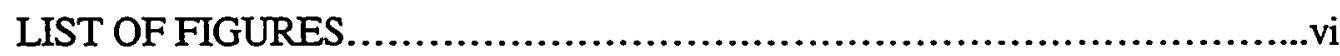

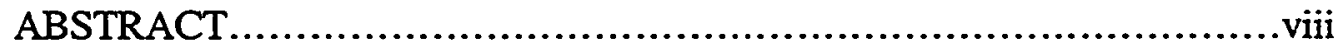

CHAPTER

PAGE

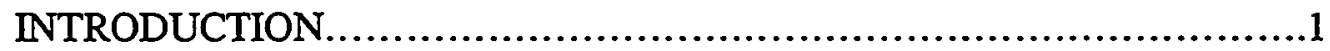

I. STIMULUS AREA, ENERGY, AND THRESHOLD PHOTOPHOBIA.....6

II. ASSESSMENT OF THRESHOLD PHOTOPHOBIA IN THE PARAFOVEA ..........................................................11

III. PHOTOPHOBIA AND RETINAL ECCENTRICITY .....................13

IV. THE RELATIONSHIP BETWEEN THE SPATIAL DISTRIBUTION OF MACULAR PIGMENT AND SPATIAL CHARACTERISTICS OF PHOTOPHOBIA....................................................14

V. METHODS (EXPERIMENTS I-III)................................. 18

Subjects................................................................18

Apparatus............................................................. 18

Procedure.................................................................... 19

VI. METHODS (EXPERIMENT IV) ..................................24

Subjects...............................................................24

Apparatus...............................................................24

Procedure...............................................................24

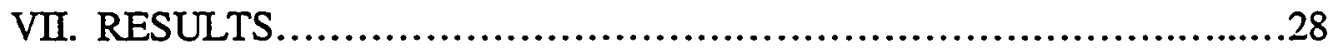

Experiment I.......................................................... 28 


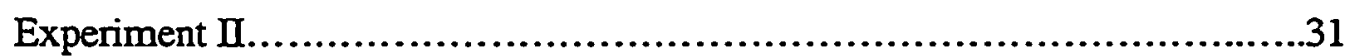

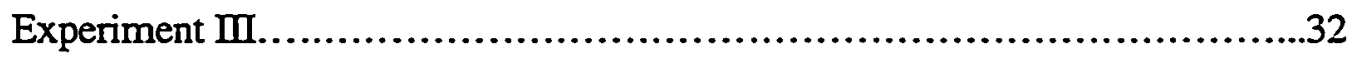

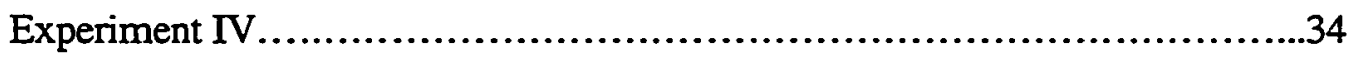

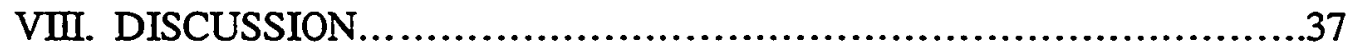

Photophobia, spatial summation, and macular pigment..........................37

A visual pathway for photophobia.............................................42

Adaptation level and photophobia...........................................47

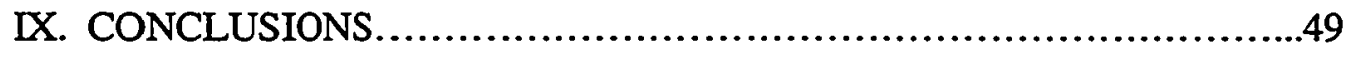

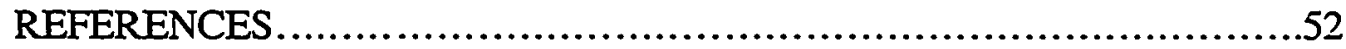




\section{LIST OF FIGURES}

Figure 1: Action spectra for photophobia (J.S. \& A.W.) corrected for macular pigment \& ocular media absorption, normalized at 500nm, compared to Ham, et al. (1976) [1000 sec. exposure]. From Stringham et al. (2003, in press). Page 3.

Figure 2: Photophobia action spectra for each subject in Stringham et al. (2003-J.S., A.W., and N.K.). Peak sensitivities are normalized to zero. Page 14.

Figure 3: Spectral emittance of xenon-arc lamp, compared to xenon passed through orange filter, and compared to macular pigment absorbance. Page 19.

Figure 4: Stimulus configuration for Experiment I. Test stimuli range from $5.6^{\circ}$ to $28.31^{\circ}$. Page 20.

Figure 5: Stimulus configuration for Experiment II. Page 20.

Figure 6: Stimulus configuration for Experiment III. Page 21.

Figure 7: A. Chart recorder. Top panel: Photocell output (amplitude spikes correspond to onset and termination of test stimulus presentation). Bottom panel: Typical threshold photophobia squint response. Note startle response (a) with ensuing brief refractory period, followed by continuous squint (b). Each thick line denotes 1 second. B. Computer-based recording. Top panel: Typical threshold photophobia squint response. Bottom panel: spike corresponding to onset and termination of test stimulus. Page 23.

Figure 8: Schematic of the stimulus used for the heterochromatic flicker photometry task in Experiment IV. Page 25.

Figure 9: Log relative radiance thresholds for photophobia to xenon-white light plotted as a function of log stimulus area (degrees ${ }^{2}$ ). Stimulus diameters (in degrees of visual angle) are noted near data points. Page 28.

Figure 10: Subjects' averaged data of log relative radiance thresholds for photophobia to xenon-white light plotted as a function of $\log$ stimulus area (degrees ${ }^{2}$ ). Stimulus diameters (in degrees of visual angle) are noted near data points. Page 29.

Figure 11: Subjects' averaged data of log relative radiance thresholds for photophobia to xenon-white light plotted as a function of log stimulus area (degrees ${ }^{2}$ ). Linear-fit slopes for the first four data points and points 5-7 are plotted for comparison. Page 29.

Figure 12: Log relative radiance thresholds for photophobia to orange light plotted as a function of $\log$ stimulus area (degrees ${ }^{2}$ ). Stimulus diameters (in degrees of visual angle) are noted near data points. Page 30. 
Figure 13: Subjects' averaged log relative radiance thresholds for photophobia to orange light plotted as a function of log stimulus area (degrees ${ }^{2}$ ). Linear-fit slope plotted for comparison. Stimulus diameters (in degrees of visual angle) are noted near data points. Page 30.

Figure 14: Log relative radiance thresholds for photophobia to xenon-white light, plotted as a function of retinal location. Page 31.

Figure 15: Log relative radiance thresholds for photophobia to orange light, plotted as a function of retinal location. Page 31.

Figure 16: Log relative radiance thresholds for photophobia to xenon-white light, plotted as a function of temporal retinal eccentricity. Page 32.

Figure 17: Log relative radiance thresholds for photophobia to orange light, plotted as a function of temporal retinal eccentricity. Page 33.

Figure 18: Horizontal and vertical meridian spatial profiles of MPOD at $460 \mathrm{~nm}$ for subject A.W. Lorentzian fit to data plotted for comparison. Page 34

Figure 19: Horizontal and vertical meridian spatial profiles of MPOD at $460 \mathrm{~nm}$ for subject M.S. Lorentzian fit to data plotted for comparison. Page 34

Figure 20: Horizontal and vertical meridian spatial profiles of MPOD at $460 \mathrm{~nm}$ for subject J.S. Lorentzian fit to data plotted for comparison. Page 34.

Figure 21: Lorentzian fits to spatial profiles of MPOD for the three subjects. Page 35.

Figures 22-24: Xenon-white area vs. intensity plots for subjects A.W., M.S., and J.S. compared to hypothetical MP-corrected functions. Page 39.

Figure 25: Log relative sensitivity (1 / radiance) for photophobia to orange light plotted as a function of stimulus radius. Logarithm of average midget (Goodchild et al., 1996), parasol (Dacey, 1993; Goodchild et al., 1996), and small bistratified (Dacey, 1993a) ganglion cell dendritic field areas plotted for comparison. Photophobia function leastsquares fit to parasol and small bistratified data. Page 43.

Figure 26: Averaged log relative radiance thresholds for photophobia to orange light, plotted as a function of temporal retinal eccentricity, compared to log relative photoreceptor spatial density (Curcio et al., 1990), and midget (Dacey, 1993), parasol (Dacey, 1994), and small bistratified ganglion cell spatial densities (Dacey, 1994). All functions normalized to the peak sensitivity value for photophobia. Page 45. 


\section{INTRODUCTION}

Photophobia is generally defined as light-induced discomfort and is a common symptom of various pathology including iritis and achromatopsia (Lebensohn, 1951), but most prominently migraine headache (Eckhardt, McClean \& Goodell, 1943; Drummond, 1986; Coleston et al., 1994; Chronicle \& Mulleners, 1996; Drummond \& Woodhouse, 1993; Drummond, 1997). Little is known about the neurophysiological processes that mediate photophobia. Because pain-signaling fibers of the trigeminal nerve terminate in the dilator and constrictor muscles of the iris, it has been suggested that the vasodilation accompanying the trigemino-pupillary reflex is the sensitizing factor that makes the pupillary light reaction painful (Lebensohn, 1934; 1951). Indeed, it has been demonstrated that an intact trigeminal nerve is necessary to experience photophobia (Lebensohn, 1934). Iris constriction, as might be expected, has been shown to increase with increasing illumination; at the point when the light intensity becomes truly discomforting, however, the iris appears to constrict and dilate irregularly every few seconds. This phenomenon is known as hippus and is thought to occur because of simultaneous, antagonistic activation of sympathetic and parasympathetic pupillary responses (Hopkinson, 1956). More recently it has been shown that hippus is not consistently associated with subjective reports of visual discomfort (Howarth et al., 1993). King (1972) suggested that the rapidity of iris constriction, and intense stretching under lighting conditions that produce maximal constriction appear to be closely related to visual discomfort. Unfortunately, these factors have proved difficult to measure, and thus cannot be reliably used as objective measures of visual discomfort. Because 
photophobia is usually thought of as coinciding with pathology, its assessment in normal subjects has been limited (Siegwart, 1920, as cited by Lebensohn, 1934; Eckhardt, McClean \& Goodell, 1943; Wirtschafter \& Bourassa, 1966). Nevertheless, photophobia is a common phenomenon experienced by anyone who has ever entered a lighted environment that is subjectively appraised as "too bright" to tolerate without aversion of some sort.

Why does a normal (subclinical) individual experience photophobia? The derivation of the answer to this question appears to follow a pathway dictated by the logic of biological protection. By definition, photophobia is discomfort, or, in extreme cases, pain brought on by intense light. Typical behavioral responses to this discomfort include squinting, wincing, directing the eyes down toward the ground (in the case of intense sunlight-Sliney, 1997), or simply looking away from the light stimulus. The perceived level of discomfort is typically commensurate with the level of aversive response. Pain is generally considered to be an adaptive response; without the sensation of pain, an organism would not survive for very long. In fact, sensory aversions (e.g., gustatory, olfactory, tactile) of all kinds appear to serve the function of survival via biological protection. With respect to photophobia, one study has provided data that speak to the issue of photophobia's role in biological protection. Using the squint response as their criterion, Stringham, Fuld, and Wenzel (2003, submitted for publication) found that, unlike common spectral sensitivity functions (e.g. photopic and scotopic spectral sensitivities), the action spectrum for photophobia, after correction for ocular media and macular pigment absorption, exhibits increasing sensitivity with decreasing wavelength (see Fig. 1). It is a well-established fact that the energy value per quantum of light is 
inversely related to wavelength. Thus, shorter wavelengths contain more energy and are potentially more damaging to biological tissue. Based on this idea, Stringham et al. (2003) have proposed that their action spectrum is indicative of an increased sensitivity to potentially damaging short-wavelength light. Other experimental results are supportive of this conclusion. Ham, Mueller, and Sliney (1976) found that the threshold (1/sensitivity) energy for retinal damage decreased with decreasing wavelength in the rhesus macaque, in a fashion similar to Stringham et al.'s (2003) corrected action spectrum for photophobia. Ham et al. (1976) used laser illumination at various wavelengths to produce a threshold change in fundus appearance, which came about as a result of retinal pigment epithelium and photoreceptor damage. When adjusted along the Y-axis for a least squares fit, the action spectrum for photophobia and Ham et al.'s (1976) data are similar; the two functions are plotted for comparison in Figure 1. Additionally, the same type of relationship has been established for threshold retinal damage in the rat (Gorgels and van Norren, 1995). It follows that an aversive

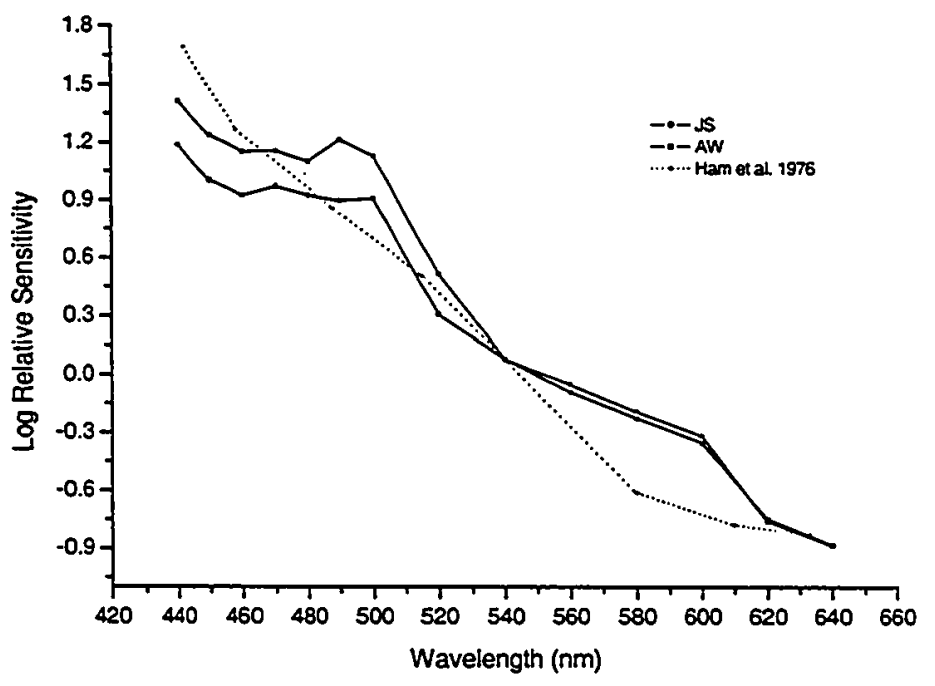

Figure 1: Action spectra for photophobia (J.S. \& A.W.) corrected for macular pigment \& ocular media absorption, normalized at $500 \mathrm{~nm}$, compared to Ham. et al. (1976) [1000 sec. exposure]. From Stringham et al. (2003, in press).

response (squint), biased toward the short wavelengths, would serve a function of biological protection. 
A more thoroughly-studied phenomenon related to photophobia is discomfort glare. Discomfort glare is generally defined as a subjective impression of discomfort upon exposure to light. Researchers studying discomfort glare have adopted subjective rating scales, termed visual analog scales. The most popular rating scale used is the de Boer visual analog scale (de Boer, 1968), with subjective ratings ranging from "just noticeable" to "unbearable." Whereas discomfort glare is certainly related to photophobia, it is difficult to make a direct comparison between the two. In discomfort glare studies, subjects are rarely, if ever, exposed to lights that are subjectively judged as “intolerable." By contrast, photophobia involves an acute intolerance to light, typically marked by some sort of behavioral aversion (e.g., squinting, or closing the eyes). There have been a few studies (Berman et al., 1994; Murray et al., 2002), however, reporting the use of electromyography as an objective ${ }^{1}$ measure of discomfort. Investigators from these studies measured the muscular activity associated with squinting and blinking around the ocular orbit upon exposure to a glare stimulus, and found good agreement with subjective ratings of discomfort. General findings from discomfort glare studies (see Waters et al., 1995) include: 1) increases in luminance give rise to increases in visual discomfort; 2) increases in pre-test adaptation luminance result in a decrease in visual discomfort; 3) increases in size of the test stimulus, while maintaining a constant luminance level, result in increased visual discomfort; 4) visual discomfort is greater for stimuli viewed centrally than peripherally; 5) discomfort thresholds measured psychophysically are especially variable among subjects.

\footnotetext{
${ }^{1}$ The term "objective" in this case is used loosely, as the measure is dependent on the subjective appraisal of the stimulus. The reader should bear this in mind for the remainder of this manuscript when the term "objective" is used in association with the electrophysiological (EMG) assessment of photophobia.
} 
Whereas Stringham et al. (2003) have determined wavelength dependence of the threshold photophobia response, the spatial properties of photophobia have yet to be investigated. The questions to be addressed in this dissertation are: 1) what is the relationship between stimulus area, energy content of the stimulus, and threshold photophobia for centrally-viewed stimuli? 2) if at all, does the threshold for photophobia change with respect to the region (i.e., nasal, temporal, superior, inferior) of the retina stimulated? 3) with a constant stimulus size, does the photophobia threshold change with increasing retinal eccentricity? 4) is there a relationship between the spatial properties of the threshold photophobia response (determined in questions 1,2 , and 3 ), and the spatial distribution of macular pigment in the retina? 


\section{CHAPTER I}

\section{STIMULUS AREA, ENERGY, AND THRESHOLD PHOTOPHOBIA}

Stringham, et al. (2003) determined wavelength dependence of the photophobia response. Beyond this finding, little is known about how basic stimulus parameters affect photophobia. Although the spatial properties for visual detection thresholds have been well established, a comprehensive, detailed assessment of the spatial properties of photophobia has yet to be performed ${ }^{2}$.

The anatomical arrangement of the cells in the retina produces the well-known centersurround organization of retinal ganglion cell receptive fields (Kuffler, 1953). Ganglion cell receptive fields (GCRFs) have been found to have one of two center-surround arrangements: on-center / off-surround, or off-center/ on-surround. If one stimulates the photoreceptors serving the excitatory center of an on-center GCRF, the ganglion cell will "fire." Increasing the area of the light stimulus to include the photoreceptors that serve the inhibitory surround will lead to less vigorous firing of the cell. If the entire GCRF is

\footnotetext{
${ }^{2}$ Of note, however, are studies by Wirtschafter and Bourassa (1966), Vanagaite et al. (1997), and Vanagaite and Stover (1998), in which binocular facilitation of visual discomfort was reported. In these studies, subjects were able to tolerate higher light levels under monocular viewing conditions than binocular viewing conditions. If one considers binocular summation a form of spatial summation, then these authors have documented a special case of spatial summation for visual discomfort that has no analog at visual threshold-under normal viewing conditions, when two spots of light are shown on corresponding retinal regions, their respective brightnesses do not sum. Levelt (1964) has proposed that there is an "averaging" of input from the two eyes, which usually results in equal brightness judgment of binocular and monocular views of a given light stimulus. Interestingly, in some cases, a binocularly-viewed spot of light is perceived as darker than when viewed monocularly. This phenomenon occurs when the two eyes are receiving different intensity input, respectively, and is known as Fechner's paradox (Helmholtz, 1866, as cited in Woodworth and Schlosberg, 1971). In the case of detection thresholds, the probability for detection increases for binocularly-as compared to monocularly-viewed stimuli. This phenomenon is known as probability summation, and reflects the increased probability of quantal catch with increases in retinal area stimulated (Guth, 1971).
} 
stimulated with diffuse light, the responses of the center and surround regions effectively cancel each other-the ganglion cell will exhibit only spontaneous firing. It has been electrophysiologically demonstrated that there is spatial summation of retinal ganglion cell center photoreceptor input (Hartline, 1940; Boycott and Dowling, 1969; Fischer, 1973). In other words, there is a "pooling" of photoreceptor input within a GCRF center in the retina.

Psychophysical investigations of spatial summation have provided results that closely approximate the electrophysiological findings regarding receptive field center summation. Generally it has been found that, up to a certain critical area, there is a perfect tradeoff between stimulus intensity and stimulus area, for detection thresholds. This relationship is described by Ricco's law (Ricco, 1877, as cited in Volbrecht, Shrago, Schefrin, and Werner, 2000), which states that, up to a critical area (known as Ricco's area), the detection threshold is the product of stimulus area and stimulus intensity. A review of the literature on spatial summation reveals the following major points. At scotopic adaptation levels, for the $7^{\circ}-10^{\circ}$ peripheral retina, many investigators have provided findings of Ricco's area that tend to converge at or near 10' (Abney, 1897; Granit, 1930; Hartline \& Graham, 1932; Graham, 1934; Graham, Brown, and Mote, 1939; Hecht, Schlaer, and Pirenne, 1942; Ratliff, 1962). The area of complete summation appears to increase, however, with increasing eccentricity, from foveal viewing out to approximately $40^{\circ}$ (Scholtes and Bouman, 1976). Because there is much less RGC convergence of photoreceptor input in the case of cones than of rods, adaptation level is an important factor with respect to spatial summation areas. For this reason, it has been found that as adaptation level increases, summation areas decrease 
(Lie, 1980). For stimuli larger than those governed by Ricco's law, particularly those viewed foveally (Pirenne and O'Doherty, 1957, as cited in Woodworth and Schlosberg, 1971; Baumgardt and Hillman, 1961), there appears to be partial summation (Hallett, 1963; Scholtes and Bouman, 1976; Zuidema, Vershuure, Bouman, and Koenderink, 1981). This partial summation is known as Piper's law (Piper, 1903, as cited in Jameson and Hurvich, 1972). Piper's law states that, for detection thresholds, the intensity of the stimulus is proportional to the square root of its area. Pirenne and O'Doherty (1957) found that Piper's law is valid for centrally-viewed, white-light stimuli as large as $47^{\circ}$. Bouman and van der Velden (1947) found Piper's law to hold for tungsten-white stimuli as large as $23.2^{\circ}$. In their study, the stimulus was centered $7^{\circ}$ in the temporal retina.

Summation areas depend heavily on the region of the retina tested, spectral content of the test light, and adaptation level of the subject (Glezer, 1965). For the purposes of the present study, the relevant data to be considered are based on "white" light or long-wave (our long-wave stimulus appears orange in color) light at mesopic or photopic levels of illumination.

In the fovea, there is little, if any, cone photoreceptor convergence onto midget ganglion cell centers (Boycott and Dowling, 1969; Goodchild, Ghosh, and Martin, 1996). As a consequence, GCRF centers in the fovea should theoretically subtend the width of only one or two foveal cone apertures (2.3-4.6 $\mu \mathrm{m}$; Curcio, 1987), which is equivalent to less than 1' of arc. Despite this anatomical evidence, which suggests little or no spatial summation in the fovea under photopic conditions, Baumgardt (1947) found Ricco's law to generally hold for stimuli up to 4' in diameter in the fovea-Ricco's area for one subject from this study was quite large-10'. To reconcile the apparent discordance 
between anatomical and psychophysical data, Banks, Geisler, and Bennett (1987) and Davila and Geisler (1991) have provided convincing evidence that spatial summation beyond the limitation of neural convergence can be explained by optical factors, namely diffraction by the pupil and chromatic abberations. To estimate optical factors that contribute to spatial summation, the researchers derived an optical point-spread function from the line-spread function of Campbell and Gubisch (1966). This estimation was "added" to an ideal observer for the purpose of predicting foveal spatial summation in real observers. This analysis was found to closely approximate the spatial summation data for their real observers, and thus provided evidence for the idea that spatial summation in the fovea can be accounted for primarily by optical factors. Apparently, these optical factors serve to blur an image, effectively "spreading" it out; this spreading of the image gives rise to an increased probability of quantal catch by neighboring cones, and results in a sort of false spatial summation.

The majority of results of studies on spatial summation appears to be accounted for by the anatomical organization of the retina-specifically, the area corresponding to the number of photoreceptor inputs to a given GCRF appears to determine the amount of summation (when optical factors are accounted for). Indeed, the size of the GCRF center has been shown to increase monotonically with increasing eccentricity from the fovea (Wiesel, 1960; Stone, 1965; Glezer, 1965; Enroth-Cugell and Robson, 1966; Fischer, 1973; Dacey, 1993). It has also been suggested that the amount of summation is inversely related to ganglion cell density (Fischer, 1973; Schefrin, Bieber, McLean, and Werner, 1998). RGC density is an inverse function of eccentricity, and, therefore, is inversely related to GCRF center size (Stone, 1965; Fischer, 1973; Wassle, Grunert, 
Rohrenbeck, and Boycott, 1989; Dacey, 1993). Given this anatomical evidence, Fischer (1973) noted that there is a nearly constant amount of overlap of GCRF centers as one moves from fovea outward in the retina. Moreover, he proposed that a constant number of GCRF centers must be stimulated to reach threshold. Upon testing this hypothesis, he found that stimulation of roughly 35 GCRF centers was required to reach a criterion physiological threshold in the cat, regardless of retinal eccentricity. These anatomical parameters appear to agree well with the available psychophysical data: As receptive field sizes increase and ganglion cell densities decrease, summation areas tend to increase. Moreover, Piper's law can be accounted for by stimulation of a combination of small and large receptive fields, which results in the intensity vs. square-root of area relationship described above. To be sure, summation areas appear to be defined by GCRF center size, whereas RGC density appears to be simply correlated with GCRF center size and, therefore, correlated with summation areas. 


\section{CHAPTER II}

\section{ASSESSMENT OF THRESHOLD PHOTOPHOBIA IN THE PARAFOVEA}

The clinical investigation of visual fields, known as visual perimetry, was developed by ophthalmologist Albrecht von Graefe in 1856 to document visual field characteristics of various eye diseases (Aulhorn and Harms, 1972). Today, specific markers for eye and visual pathway pathology, ascertained from visual field assessment, are well known to ophthalmologists. For example, macular degeneration, homonymous hemianopsia (in the event of optic nerve damage), and scotomas characteristic of glaucomatous damage are all easily identified with the visual perimeter.

In static visual perimetry, visual fields are tested by presenting patients small, brief flashes of light to one eye, in various regions of the visual field. The lights are presented on a photopic-level background. The luminance threshold for detection of the spot of light is determined for each region of the visual field tested. Because visual perimetry has been used for many years, certain characteristics of normal visual fields have been well documented. For example, it is known that isopters (iso-sensitivity lines) do not form concentric circles about the fovea-they tend to form complex shapes (Harrington, 1981). Characteristic of normal visual fields is a steeper "slope" of sensitivity with eccentricity in the temporal retina than in the nasal retina (Inui, 1981). In other words, whereas there is a drop off in sensitivity with eccentricity for both temporal and nasal retinas, the nasal retina tends to be slightly more sensitive than temporal for all eccentricities, save the blind spot. To a lesser extent, the sensitivity of the superior retina 
has been shown to be slightly higher than that of the inferior retina. For the purposes of the present study, differences in sensitivity among the retinal regions within the parafovea are very small (Aulhorn and Harms, 1972).

For the present study, the term "parafovea" is defined as the circular retinal region tangent to and extending $5.6^{\circ}$ from the center of the fovea (see Fig. 5 for stimulus arrangement). Testing of the parafovea was chosen for this study, as potential differences in photophobia sensitivity of these regions may be explained by related differences in the spatial distribution of the macular pigment (see chapter IV). 


\section{CHAPTER III}

\section{PHOTOPHOBIA AND RETINAL ECCENTRICITY}

As stated in the previous section, there have been numerous perimetry studies that have determined visual sensitivity at photopic levels of adaptation as a function of retinal eccentricity (see Auinom and Harms, 1972). For lights that are subjectiveily judged to be on the border between comfort and discomfort, sensitivity decreases as a function of retinal eccentricity (IES Lighting Handbook, 1981). In other words, lights that are centrally viewed produce discomfort at lower light levels than those in the periphery. It is unknown, however, how sensitivity to lights that produce photophobia changes with retinal eccentricity. The goal of this experiment is to determine how threshold photophobia to xenon-white and "orange" lights changes with eccentricity. The white and orange stimuli were chosen for comparison because the macular pigment (see below) absorbs some (a portion of the short-wavelengths) of the white, but none of the orange (which contains no short-wavelength energy). Because the macular pigment is located in the central retina, there could be relative differences in photophobia thresholds for centrally- and peripherally-viewed white and orange stimuli. 


\section{CHAPTER IV}

\section{THE RELATIONSHIP BETWEEN THE SPATIAL DISTRIBUTION OF MACULAR PIGMENT AND SPATIAL CHARACTERISTICS OF PHOTOPHOBIA}

Strong evidence for the notion that photophobia may be affected by the macular pigment was provided by Stringham et al. (2003). Their subjects' photophobia action spectra exhibited a large "notch," or general decrease in sensitivity in the short wavelength region, with a minimum sensitivity point corresponding to $460 \mathrm{~nm}$ (Fig. 2).

A possible explanation for the pronounced notch found in Stringham et al.'s (2003) subjects' functions is the absorption of light by macular pigment (MP).

The carotenoids lutein

(L) and zeaxanthin (Z) collectively compose MP. $\mathrm{L}$ and $\mathrm{Z}$ are found throughout the retina (Handelman et al., 1988), but

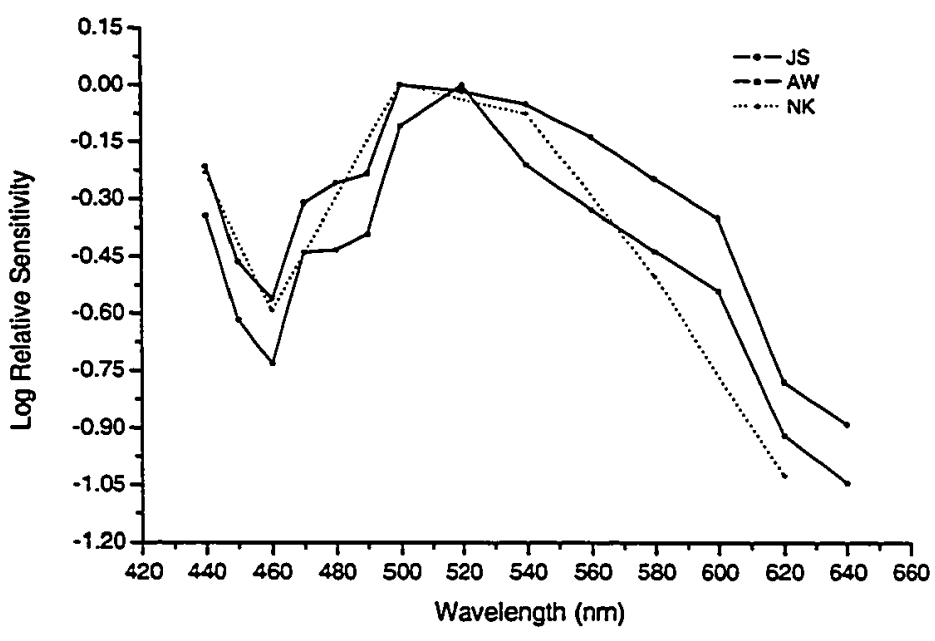

Figure 2: Photophobia action spectra for each subject in Stringham et al. (2003-J.S., A.W., and N.K.). Peak sensitivities are normalized to zero.

are, for reasons unknown, preferentially deposited in relatively high concentrations in the inner plexiform and photoreceptor axon layers of the macula (Snodderly, Brown, Delori, \& Auran, 1984b). $\mathrm{L}$ and $\mathrm{Z}$ are known as xanthophylls, designated as such by their molecular structure-xanthophylls exhibit a six-carbon ring, that contains oxygen, at each end of their carbon-conjugated double bond chains. This structure enables $L$ and $Z$ 
to effectively protect biological tissue in two ways. First, by virtue of their carbonconjugated double bonds, these carotenoids can "quench" the energy of damaging singlet oxygen and other free radical species through a process called triplet excitation transfer. In sum, this process involves energy transfer reactions in which the energy of singlet oxygen and other free radicals is transferred to carotenoid molecules in the ground state, which results in the formation of triplet state carotenoid molecules. The energy acquired by the carotenoids is then lost as heat, and the ground state carotenoid is regenerated to undergo another cycle of photoprotection (Krinsky et al., 2003). Second, $L$ and $Z$ (which are yellowish in color) selectively absorb high-energy, potentially damaging shortwavelength light. Upon absorption, the energy is dissipated as heat. From the available data, the two roles (antioxidant, and short-wave light filter) played by retinal $\mathrm{L}$ and $\mathrm{Z}$ appear to protect the macula from acute damage, protect against cumulative damage resulting in age-related macular pathology (Snodderly, 1995), and maintain visual sensitivity over a lifetime (Hammond, Wooten, and Snodderly, 1998).

$\mathrm{L}$ and $\mathrm{Z}$ are not synthesized by the body, and therefore are obtained via dietary intake (Khachik et al., 1992b). Leafy-green vegetables such as spinach, kale, and broccoli contain high concentrations of $L$, and to a lesser extent, $Z$. Other foods, such as orange peppers, contain high concentrations of $Z$. Several studies have documented positive correlations between MP level and dietary consumption of $L$ and $Z$ (e.g., CurranCelentano et al., 2001).

MP's hypothesized protective role against damaging short-wavelength light, suggested first by Schultze (1866, as cited by Werner, Donnelly, \& Kliegl, 1987) is particularly germane to the study of photophobia. The wavelength of peak absorption for MP is 460 
nm (Wyszecki \& Stiles, 1982; Vos, 1972; Bone, Landrum, \& Cains, 1992), which is precisely where the point of minimum sensitivity within the short-wavelength "notch" was found in Stringham et al.'s (2003) observers' functions. MP is radially symmetric about the foveola; the optical density of MP decreases exponentially from its peak in the foveola outward to an asymptote at approximately $5^{\circ}$ of angular subtense (Snodderly, Auran, \& Delori, 1984a; Bone, Landrum, Fernandez, \& Tarsis, 1988; Hammond, Wooten, \& Snodderly, 1997). Given the spatial distribution of MP, it could be that as short-wave-containing stimuli (such as the the xenon-white stimuli from Experiment $I$ ) are increased in size, the relative effectiveness of MP's absorption will decrease. Moreover, the orange lights (which spectrally avoid MP absorption) from Experiment I may produce a function different from the xenon-white-derived function.

With regard to Experiment II (assessment of photophobia in the parafovea), Hammond et al. (1997) showed that MP is symmetrically distributed along the horizontal and vertical retinal meridians. This conclusion should be considered tentative, however, as it was based on data obtained from only one subject. If our subjects are found to have asymmetrical distributions of MP, we expect increased photophobia sensitivity to the xenon-white light in the parafovea corresponding to regions where there is relatively less MP.

During the course of their study, Stringham et al. (2003) found preliminary evidence for spatial summation of the photophobia response over relatively large field sizes (from 1 to 6 degrees). Based on this, they hypothesized that photophobia thresholds are determined by retinal mechanisms summed over the total area stimulated by the test field. Thus, the attenuation factor by MP was determined by a spatial integration of MP optical 
density (MPOD). This kind of determination of integrated MPOD results in a much higher value than that determined by conventional methods (e.g., heterochromatic flicker photometry—see, e.g., Werner, Donelly, and Kliegl, 1987), and suggests that MP may play a very important role in the attenuation of the photophobia response.

Peak MP values and spatial profiles of MP distribution vary widely among subjects (Hammond et al., 1997; Chen, Chang, \& Wu, 2001). This, coupled with the finding that the photophobia response appears to be strongìy affected by MiP ieveis (Stringham et ai., 2003), suggests comparison be made of the spatial properties of photophobia and spatial distribution of MP. The goal of this experiment is to document detailed spatial profiles along the horizontal and vertical meridia of the three subjects. Comparison of the spatial properties of photophobia (obtained from Experiments I, II, and III) with individual detailed spatial profiles of MP should provide the basis for firm conclusion as to the relationship between photophobia and MP. 


\section{CHAPTER V}

\section{METHODS (EXPERMMENTS I-II)}

\section{Subjects}

Two males, 32 and 30 years of age, and one female, 34 years of age, served as subjects for this study. Aiỉ subjects underwent standard visuai perimetric assessment (Octopus perimeter, Interzeag Company) to confirm normal visual fields and to document the exact location, size, and shape of each subject's blind spot. None of the subjects has a history of visual pathology.

\section{Apparatus}

A three-channel standard Maxwellian view system with a $1000 \mathrm{~W}$ xenon arc lamp was used. In one channel, a xenon-white, $30.5^{\circ}$, mesopic level $\left(-1 \log \mathrm{cd} / \mathrm{m}^{2}\right)$ background field served to maintain subjects' adaptation level prior to presentation of the test stimulus. The second channel was used to present a 20', red fixation point. The third channel provided the test stimulus, either a xenon-white or orange disk of light ranging from $5.6^{\circ}$ to $28.31^{\circ}$ of visual angle. The orange-colored stimulus was created by passing xenon-white light through a Tiffen \#15 long-pass optical filter, which cuts on at approximately $540 \mathrm{~nm}$. Because macular pigment absorbs light from approximately 400 $\mathrm{nm}$ to $530 \mathrm{~nm}$, use of this filter for producing photophobia precluded effects of macular pigment absorption. The spectrum of the xenon arc and orange filter can be seen plotted together with the macular pigment absorption spectrum in Figure 3. Neutral-density filters and a neutral-density wedge were used to adjust the intensity of the test stimulus. 
The diameter of the

xenon arc image

conjugate with the

pupil was $1.25 \mathrm{~mm}$.

Photophobia-

inducing energy

ieveis were measured

after each session

with a radiometer

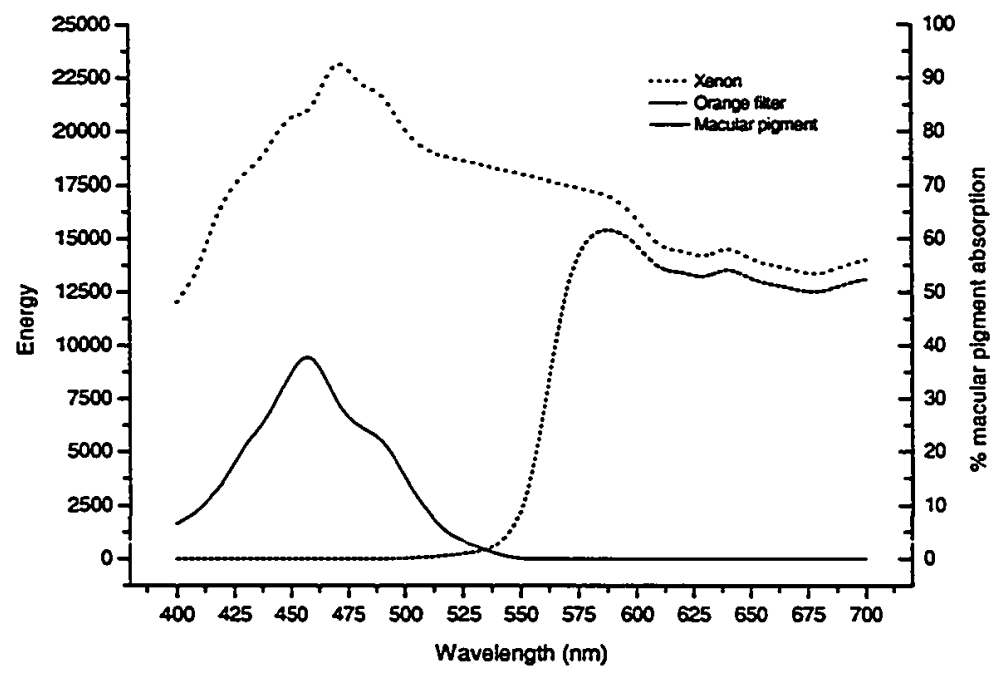

Figure 3: Spectral emittance of xenon-arc lamp, compared to xenon passed through orange filter, and compared to macular pigment absorbance.

(United Detector Technology model Optometer 61).

A criterion squint response, measured with an EMG, served as the operational definition of threshold photophobia. This method proved to yield reliable results in a previous study (Stringham et al., 2003). To assess subjects' squint responses, a Grass Instruments model 7P3B EMG preamplifier/amplifier, routed through a signal integrator, was coupled to one channel of a computer-based waveform analyzer/recorder. For precise determination of the portion of the recording that corresponded to stimulus presentation, the switch used to open the test channel shutter was wired to send a pulse to the second channel of the computer.

\section{Procedure}

Experiment I assessed the photophobia threshold for centrally-viewed xenon-white or orange stimuli that varied in size from trial to trial. The test stimuli were concentric with the background field. The dimly-lit red fixation point remained in the center of the background field, to ensure central viewing of the test stimulus (Fig. 4). For Experiment 
II, which assessed photophobia thresholds to a $5.6^{\circ}$ stimulus in the parafovea of nasal, temporal, superior, and inferior retina, the fixation point was positioned in a location that allowed for placement of the test field in the retinal region of interest. For example, if the test stimulus were to appear in the inferior retina, the fixation point was

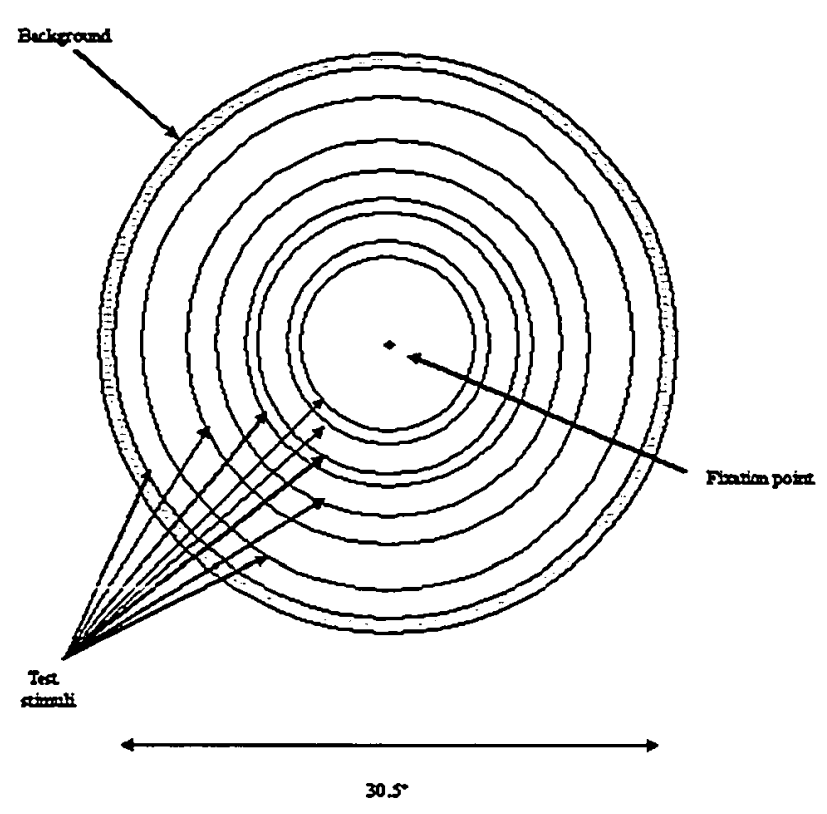

Figure 4: Stimulus configuration for Experiment l. Test stimuli range from $5.6^{\circ}$ to $28.31^{\circ}$. See text for explanation. placed tangential to the lower rim of the test stimulus (Fig. 5). For Experiment III, which assessed photophobia thresholds to a $9.52^{\circ}$ stimulus viewed centrally and at two

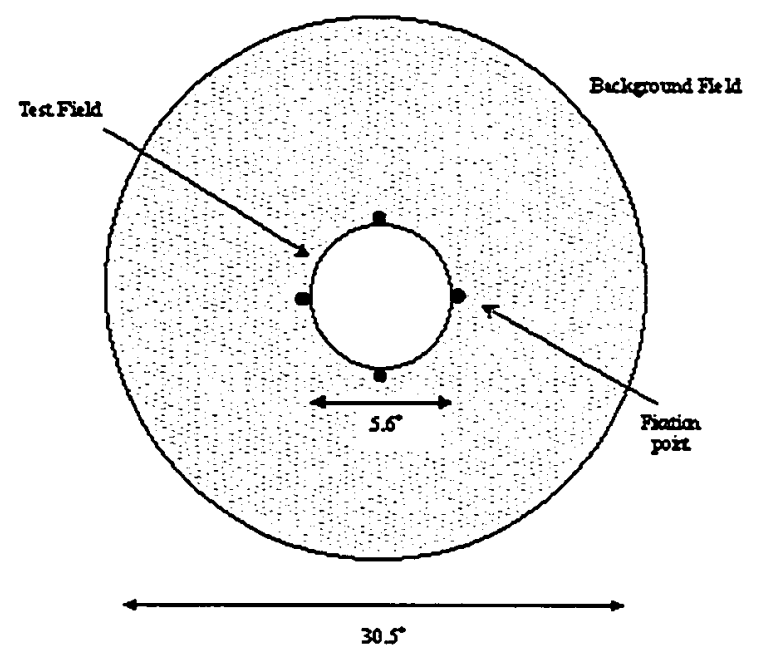

Figure 5: Stimulus configuration for Experiment II. See text for explanation. peripheral locations $\left(10^{\circ}\right.$ and $\left.20^{\circ}\right)$ in the temporal retina, the fixation point was placed the desired distance to the right of the test stimulus (Fig. 6).

Subjects maintained a stable alignment by biting down on a pre-made dental impression and leaning their head against a forehead-rest assembly. A pupillary alignment procedure was performed to

ensure that the light from the optical system was in focus in the plane of the subject's pupil and passing through the center of the subject's pupil. The subjects initially dark- 
adapted for 15 minutes. The background field was then presented, and the subject was instructed to fixate the fixation point placed in the center of the background field (Experiment I-see Fig. 4), or in one of four (right, left, top, bottom) tangential test field locations (Experiment $I I$-see Fig. 5), or in a $10^{\circ}$ or $20^{\circ}$ location to the right of the center of the to-be-viewed test stimulus (Experiment II-see Fig. 6). After one minute, the subject was presented with the test stimulus for five seconds. The two shutters in the optical system were wired out-of-phase with respect to each other, which allowed for an exact exchange of the background and test fields. The background field subtended $30.5^{\circ}$, whereas the test stimuli (Experiment $\mathrm{D}$ ) were one of eight sizes: $5.6^{\circ}$,

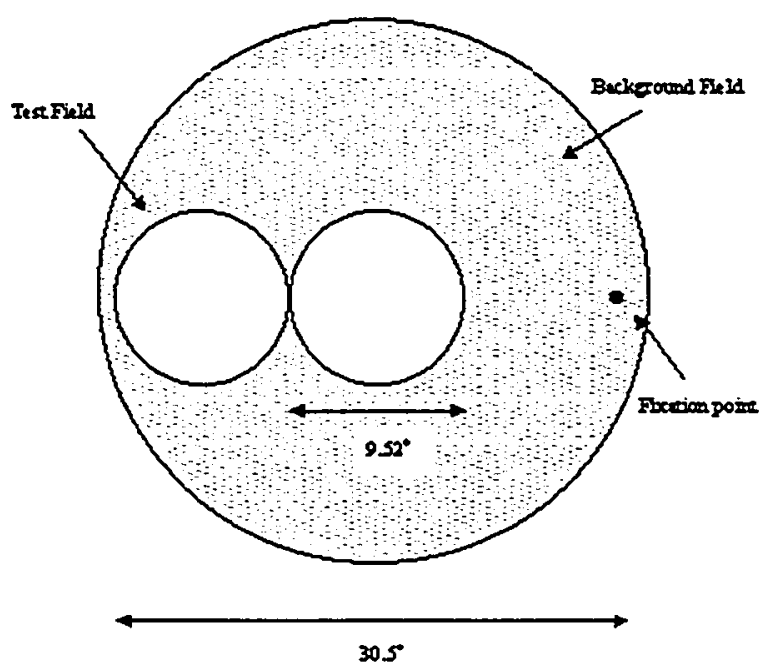

Figure 6: Stimulus configuration for Experiment III. See text for explanation.

$6.83^{\circ}, 8.16^{\circ}, 9.52^{\circ}, 12.43^{\circ}, 16.91^{\circ}, 22.34^{\circ}$, or $28.31^{\circ}$. The background field was

therefore always larger than the test stimulus-by at least $2.19^{\circ}$. Cornsweet (1956) showed that, during fixation, minor involuntary eye drifts do not exceed 6.6' of visual angle. Gleezer (1965) found the maximum drift angle during fixation to be approximately $10^{\prime}$. Therefore, in the case of minor drifting eye movements, the larger background field in the present study ensured an equal adaptation of the retinal area to be stimulated by the test field. This arrangement also ensured that, while viewing the test stimulus, a subject's minor eye movements would not train the test stimulus onto an area of the retina that was outside the $30.5^{\circ}$ subtense of the background / adaptation field, and, 
therefore, more dark adapted. For subsequent trials, the subject dark adapted for approximately 10 minutes post-test and was then instructed to view the mesopic-level background. The background was flashed on and off by the experimenter and the subject was asked if a residual afterimage from the previous trial was present. The perception of an afterimage necessitated additional dark adaptation in order to reach the mesopic threshold. At the point when no afterimage was present, the procedure, as described above, ensued.

Photophobia was assessed by recording the muscle potentials associated with subjects' squint responses, via an EMG. Surface electrodes were attached to the right temple (reference), upper cheek, below the lateral canthus of the right eye (test) and on the back of the neck (ground). The EMG was used solely for the determination of a threshold photophobia response; the criterion threshold photophobia response was based on the amplitude and duration of squint. A continuous squint response that lasted at least onehalf the duration of the test stimulus presentation and that reached, at any point during the continuous squinting, a 4:1 signal-to-noise ratio (squinting activity / baseline) was considered a threshold photophobia response. These criteria were determined to be strongly correlated with the subjective experience of discomfort during preliminary testing for a previous study (Stringham et al., 2003). Stringham et al. (2003) found that a subject will often blink or exhibit a "startle squint" upon presentation of the test stimulus, followed by normal fixation or some squinting (depending on the discomfort caused by the test stimulus) for the remainder of the stimulus presentation. This startle reaction is the well-known photic startle response (Yates \& Brown, 1981). On traces where the photic startle response was evident, neither its amplitude nor its duration was factored 
into the photophobia threshold criteria. Figure 7 shows examples of typical criterion photophobia responses.

The method of ascending limits was employed for all of the experiments. A relatively low-intensity test stimulus was initially presented, and, in steps separated by dark adaptation, the intensity of the stimulus was increased, in increments of 0.10 iog unit, untii the photophobia threshoid was reached. Stimuli were presented in a random fashion, with stimulus size (or location, depending on the experiment) drawn from a box containing all possible outcomes for a given experiment.

For Experiment I, a total of four sessions were required to complete assessment at all eight stimulus sizes for white and orange. To normalize results from the two sessions within each light condition, a photophobia threshold measure for $9.52^{\circ}$ was taken during each session. In this way, any response variability arising from differences in electrode placement, subjects' day-to-day absolute sensitivity, or output of the optical system was offset by a scalar shift along the axis of ordinates. Experiments II and III, respectively, were completed in two sessions (one each for white and orange).
\&

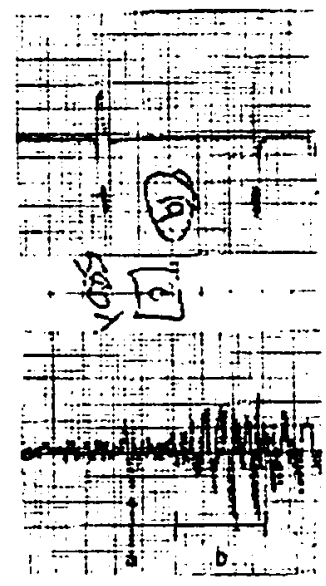

B
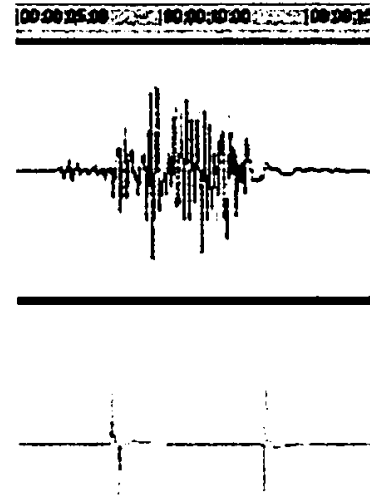

Figure 7: A. Chart recorder. Top panel: Photocell output (amplitude spikes comespond to onset and termination of test stimulus presentation). Bottom panel: Typical threshold photophobia squint response. Note startle response (a) with ensuing brief refractory period. followed by continuous squint (b). Each thick line denotes 1 second. B. Computer-based recording. Top panel: Typical threshold photophobia squint response. Bottom panel: spikes corresponding to onset and termination of test stimulus.

Experiments I, II, and III were performed twice for each subject. Each point on the plots from the results of Experiments I-III is the midpoint of two thresholds. 


\section{CHAPTER VI}

\section{METHODS (EXPERIMENT IV)}

\section{Subjects}

The same three subjects from Experiments I-III participated in Experiment IV. Apparatus

A slightly modified device described by Wooten, Hammond, Land, and Snodderly (1999), was used to obtain spatial profiles of macular pigment optical density (MPOD). The device features seven roughly monochromatic LEDs, four with emission maxima at $470 \mathrm{~nm}$, two with emission maxima at $458 \mathrm{~nm}$, and one with an emission maximum at $570 \mathrm{~nm}$. The four $470 \mathrm{~nm}$ LEDs produce the background upon which the test stimuli are presented. The two $458 \mathrm{~nm}$ LEDs are electronically driven in square-wave counterphase with the $570 \mathrm{~nm}$ LED to produce a flickering test stimulus. Light from the background channel is collimated with a planoconvex lens and passes through an aperture that yields a disk of light subtending $6^{\circ}$ of visual angle. The test stimulus channel is collimated with a planoconvex lens and defined by selectable apertures from a variable-aperture shutter box. The two channels are then combined by a beam splitter. This arrangement allows the subject to view, with his/her right eye, the flickering test stimulus placed upon the background field (see Fig 8).

\section{Procedure}

This device allows for the use of the method of heterochromatic flicker photometry (HFP) to measure MPOD. The test stimulus comprises a $458 \mathrm{~nm}$ light, which is very 


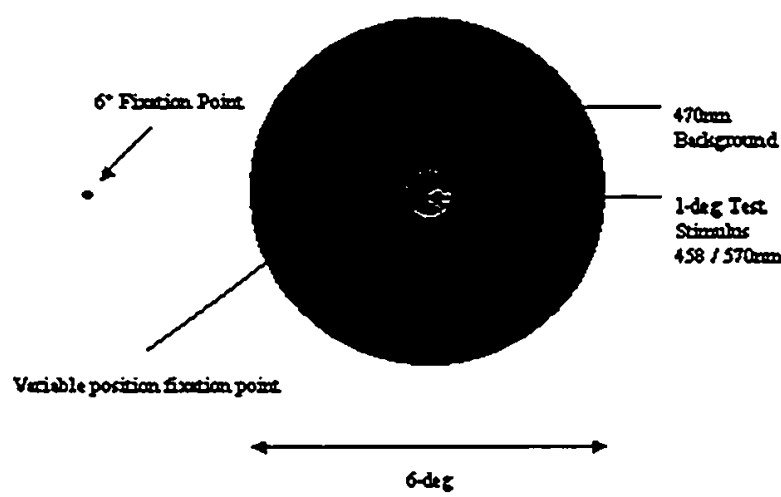

Square-wave ceumterghase presentation of rest stimulus

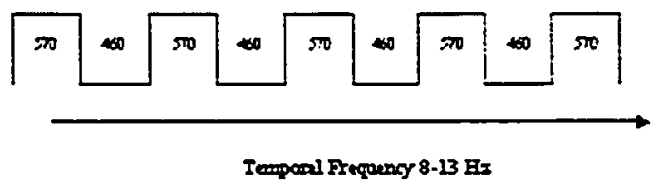

Figure 8: Schematic of the stimulus used for the heterochromatic flicker photometry task in Experiment IV. near the peak absorbance wavelength for MP (460 nm), presented in square-wave counterphase with a 570 $\mathrm{nm}$ light, a wavelength of which MP absorbs only approximately $1 \%$. The $458 \mathrm{~nm}$ and $570 \mathrm{~nm}$ disks of light are aiternated at frequencies from 8 to 13 $\mathrm{Hz}$, depending primarily on the retinal locus tested. The frequency used is adjustable, and determined by the experimenter to be one that yields the smallest possible variability in subject response. The perceptual quality of the test stimulus is that of a flickering disk. The task for the subject in this experiment is to adjust the radiance of the $458 \mathrm{~nm}$ component of the test stimulus in such a way as to eliminate the flicker from the disk. This occurs when the $458 \mathrm{~nm}$ and $570 \mathrm{~nm}$ lights have the same effective luminance (known as sensation luminance--Kaiser, 1988) for the subject. The relative energy for flicker elimination at this retinal locus is then compared to the relative energy needed for flicker elimination at a location in the retina that is known to contain very little or no MP (i.e., $7^{\circ}$ retinal eccentricity). The log ratio of the two yields a measure of MPOD at the first retinal locus.

Because the accurate determination of MPOD using HFP is dependent upon stable relative chromatic sensitivity within the retinal region tested, isolation of M- and L-cones is necessary, as it was shown by Cicerone and Nerger (1989) that the ratio of M- to L- 
cones is relatively stable from the foveola to $7^{\circ}$ retinal eccentricity. By contrast, the distribution of S-cones and rods changes dramatically across the macula (Østerberg, 1935; Curcio et al., 1991). The first way in which the stimulus conditions described above favor M- and L-cone input to complete the HFP task is the use of the short-wave background field. This field is more strongly absorbed by S-cones and rods and therefore minimizes their contribution to null flicker judgments. Moreover, the use of a flickering stimulus at a frequency above that of S-cone and rod flicker fusion thresholds ensures completion of the HFP task via M- and L-cones.

To determine values for MPOD near the foveal center, subjects viewed centrally two stimuli, 40' and 60' in diameter, respectively. It has been shown that HFP thresholds are largely determined by receptors stimulated by the edges of the test fields used (Wemer et al., 1987). Thus, the derived optical density values are for MP at the retinal loci comesponding to where the edges of the field are. For example, by using a $60^{\prime}$ test stimulus, an estimate of MPOD at 30' (the radius of the test field) retinal eccentricity is obtained. For values beyond $2^{\circ}$ retinal eccentricity, MPOD is conventionally measured via use of a fixation point placed outside the test stimulus. This enables the experimenter to train the flickering test stimulus on a retinal location determined by the angle of fixation, relative to the test stimulus. Because the goal of this experiment was to obtain spatial profiles of MPOD, the subject performed the flicker-elimination task at several retinal loci. This was achieved through use of a variable-position fixation point. For example, if the $3^{\circ}$ nasal portion of the horizontal meridian were tested, the fixation point (a very small black dot) was placed $3.5^{\circ}$ to the left of the flickering $1^{\circ}$ test disk $\left(3.5^{\circ}=3^{\circ}\right.$ beyond the edge of the $1^{\circ}$ test stimulus). For Experiment IV, detailed spatial profiles of 
MPOD along the horizontal and vertical meridia were obtained for each subject. MPOD measures were made at $20^{\prime}, 30^{\prime}, 60^{\prime}, 90^{\prime}, 150^{\prime}$, and $300^{\prime}$ retinal eccentricities in each of the four major retinal quadrants (superior, inferior, temporal, nasal). Six measures of sensation luminance were made at each retinal locus. Two sets of MPOD profiles were obtained for each subject. The order of retinal locus testing was counterbalanced with respect to session, to control for potential order effects. The averaged profiles were compared to the data obtained in Experiments $\bar{I}, \bar{I}$, and III to determine any reiationship between the spatial properties of photophobia and the spatial distribution of MP. For example, if a subject exhibited some form of spatial summation from the results of Experiment I (xenon-white), the level of spatial summation (slope of area vs. intensity curve) was compared to the peak MPOD value and the slope of the MPOD spatial distribution. Furthermore, if regional differences in photophobia sensitivity were found in Experiments II or III, corresponding MPOD levels in those regions were examined to determine if MP could account for the sensitivity differences. 


\section{CHAPTER VII}

\section{RESULTS}

\section{Experiment I (Spatial summation and photophobia)}

For the xenon-white light condition, subjects' area vs. intensity functions are shown in Figure 9. The data are non-normalized, and are plotted in terms of log relative radiance. The functions are quite similar in shape and scale, and the error bars $(+/-1.0$ standard deviation) indicate low variability. From Figure 9 , it can be seen that the radiance necessary to induce photophobia decreases approximately monotonically as stimulus area increases. In other words, there appears to be some spatial summation for photophobia, to xenon-white light.

Beyond this generality, the functions have another noteworthy point in common: The "tails", made up of the final four points on the abcissa, are strikingly similar in shape and exhibit very low

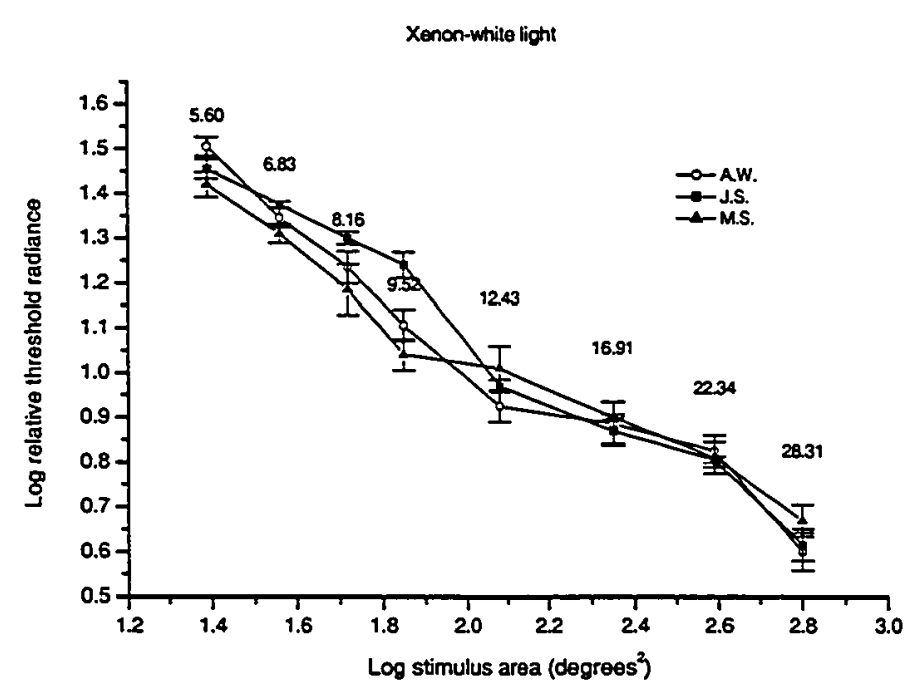

Figure 9: Log relative radiance thresholds for photophobia to xenonwhite light plotted as a function of $\log$ stimulus area (degrees ${ }^{2}$ ). Stimulus diameters (in degrees of visual angle) are noted near data points.

variability among subjects. By contrast, the first four points of the functions exhibit relatively higher between-subject variability. When the subjects' three functions are averaged and fit with a linear function, the slope is found to be -0.56 (Fig. 10). 
Photophobia to xenon-

white light therefore

appears roughly to conform

to Piper's law: The

intensity of the

photophobia-inducing

stimuius is approximateiy

proportional to the square

root of its area. A linear

function, however, does not

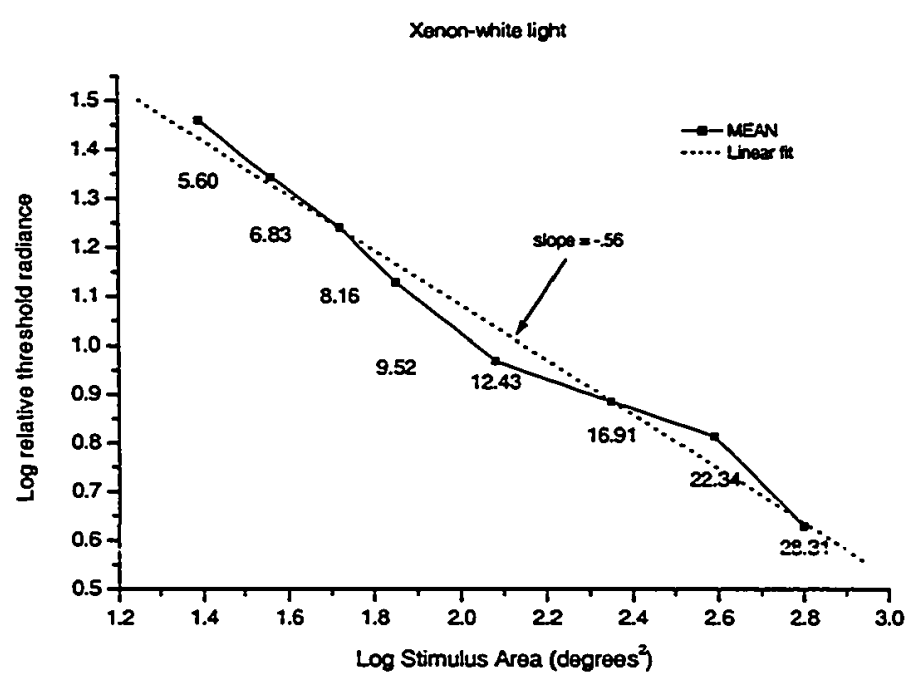

Figure 10: Subjects' averaged data of log relative radiance thresholds for photophobia to xenon-white light plotted as a function of $\log$ stimulus area (degrees ${ }^{2}$ ). Stimulus diameters (in degrees of visual angle) are noted near data points.

adequately describe the data. Upon closer examination, the first five points of the average function appear to comprise a function with a steeper slope than that composed of points 5-7. Indeed, if the first five points are averaged and linearly fit, the slope is

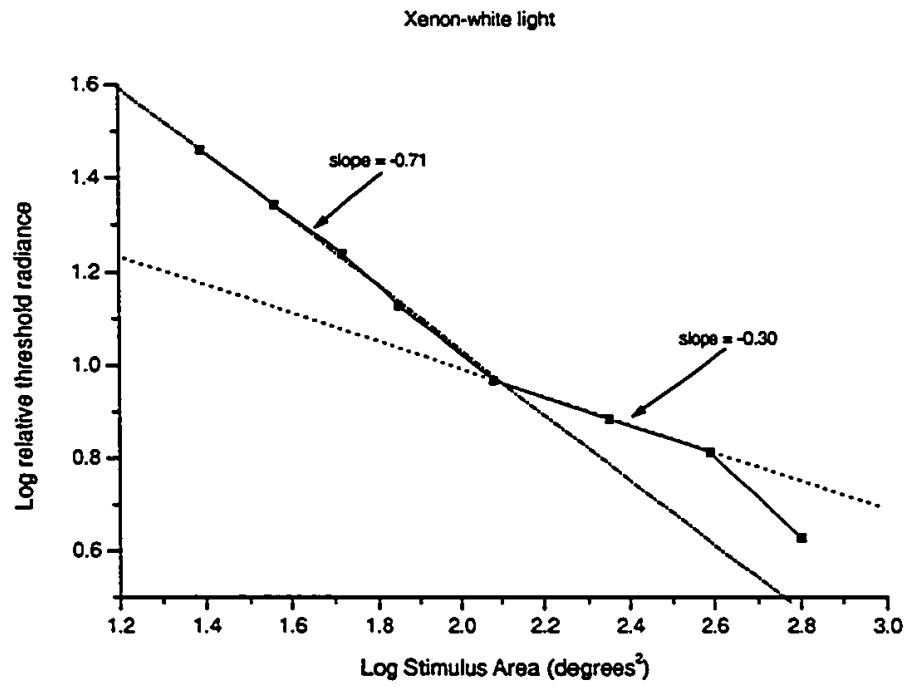

Figure 11: Subjects' averaged data of log relative radiance thresholds for photophobia to xenon-white light plotted as a function of log stimulus area (degrees'). Linear-fit slopes for the first four data points and points 5-7 are plorted for comparison. found to be -0.71 , whereas

for points 5-7, a much less

steep linear-fit slope of -

0.30 was determined (Fig.

11). Data point number

eight was not used in the

linear fit, as it does not

reconcile linearly with

points 5-7. Perhaps data

point number eight marks 
the beginning of a

different branch of

photophobia summation

for xenon-white light.

This analysis (of the

averaged function) was

performed despite the

apparent variability among

the subjects for the first

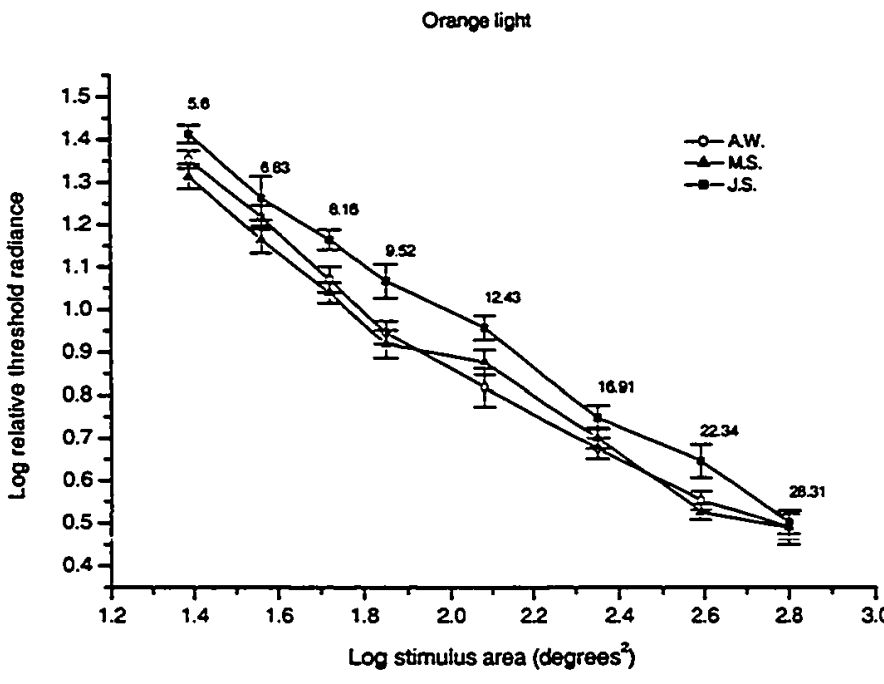

Figure 12: $\log$ relative radiance thresholds for photophobia to orange light plotted as a function of $\log$ stimulus area (degrees'). Stimulus diameters (in degrees of visual angle) are noted near data points.

five (especially the first four) data points. It was assumed that the averaging yielded an approximation of an average observer's function.

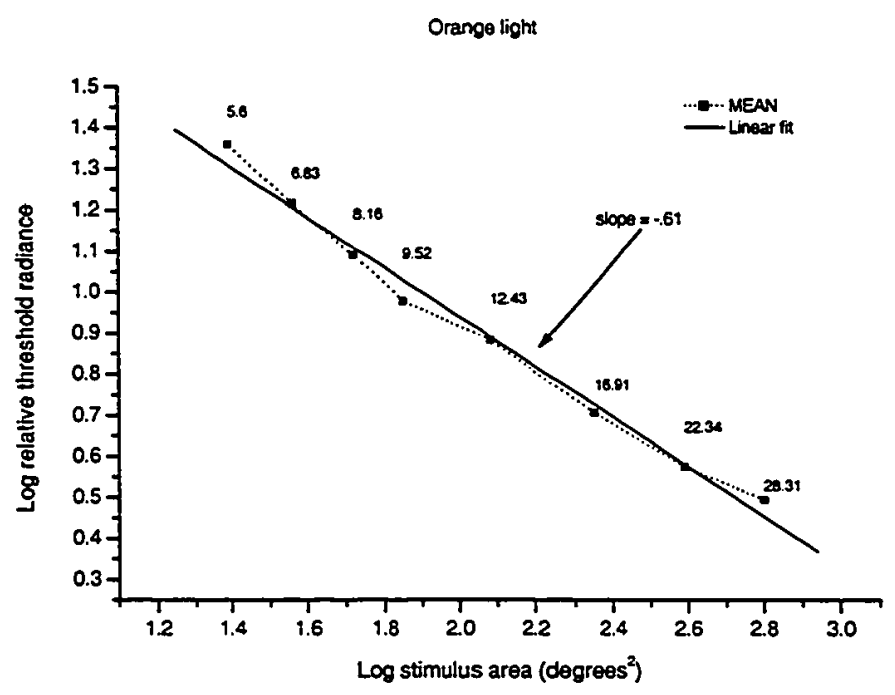

Figure 13: Subjects' averaged log relative radiance thresholds for photophobia to orange light plotted as a function of log stimulus area (degrees ${ }^{2}$ ). Linear-fit slope plotred for comparison. Stimulus diameters (in degrees of visual angle) are noted near data points.
For the orange light condition, subjects' area vs. intensity functions are shown in Figure 12. The error bars indicate low within-subject variability. Moreover, there is very little between-subject variability with respect to the shape of the functions. Whereas the

xenon-white functions exhibit at least two branches of summation, the orange light condition appears to have yielded area vs. intensity functions that are approximately 
linear. When the subjects' functions are averaged and fit with a linear function, the slope is found to be -0.61 (Fig. 13). Summation for photophobia to the long-wavelength orange light is therefore greater than that dictated by Piper's law (slope of -0.5 ), but substantially less than that of perfect summation (Ricco's law, slope of -1.0). From Figure 12 it can be seen that subjects A.W. and M.S. were found to have very similar radiance requirements, at all stimulus sizes, to reach photophobia threshold. Both

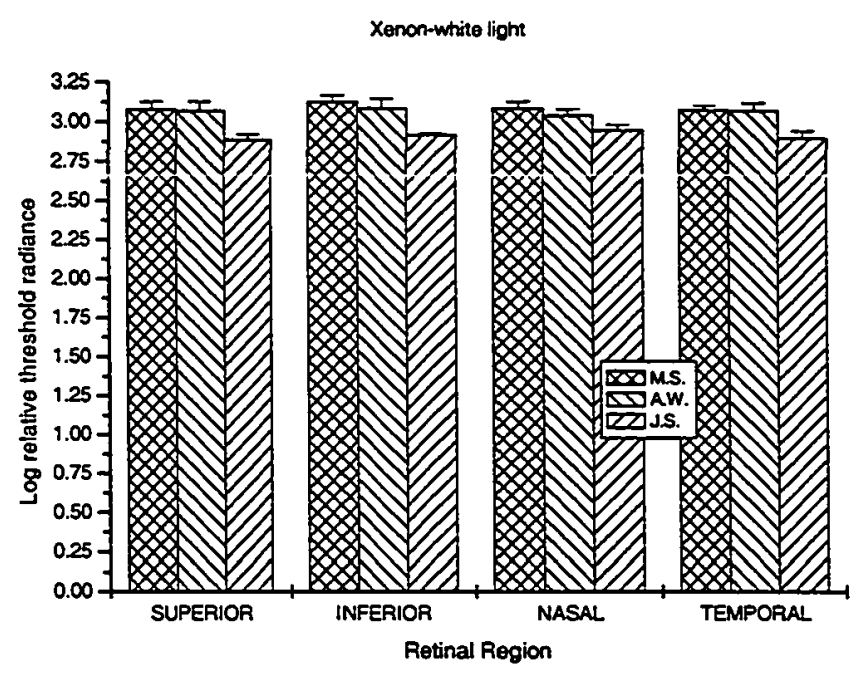

A.W. and M.S. differ from

subject J.S., who

systematically required a

higher radiance level for threshold photophobia at all the stimulus sizes tested. Experiment II (Photophobia in the parafovea)

Figure 14 graphically

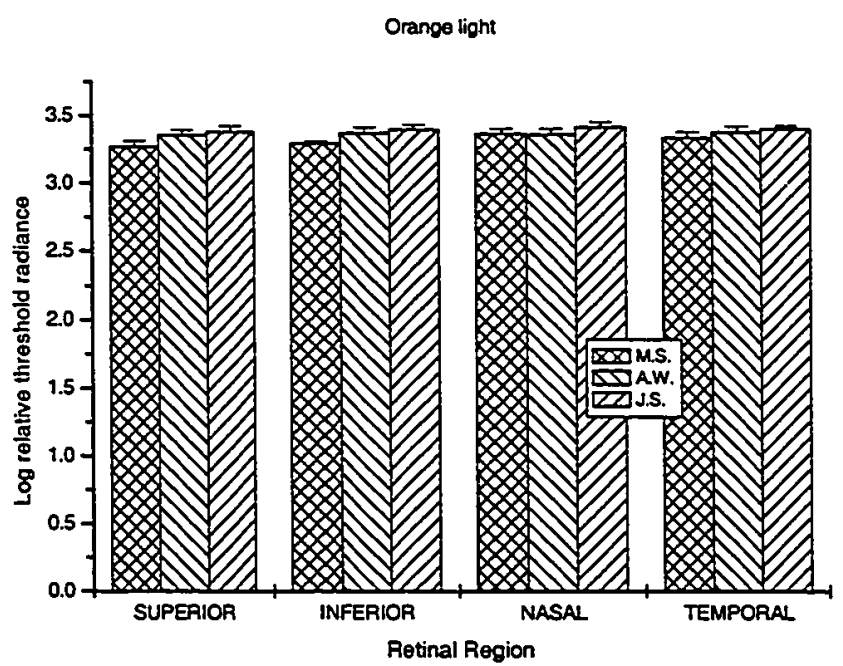

Figures 14 (top) and 15: Log relative radiance thresholds for photophobia to xenon-white and orange light, plotted as a function of retinal location.

depicts the results of Experiment II for xenon-white light. The three subjects exhibited very little within-subject variability with respect to retinal region. At each retinal region 
tested, subject J.S. required less energy to elicit a threshold photophobia response. In contrast, subjects M.S. and A.W. were very similar in their radiance requirements to reach photophobia threshold. Results for the orange light condition are presented in Figure 15.

\section{Experiment III (Photophobia and retinal eccentricity)}

To disentangle the parameters of stimulus size and retinal location, Experiment $\mathrm{II}$ tested photophobia threshoids to $9.52^{\circ}$ discs of xenon-white and orange light at three retinal locations: Centrally-viewed, $10^{\circ}$, and $20^{\circ}$ temporal retinal eccentricity. Results for the xenon condition are presented in Figure 16. For the centrally-viewed xenon

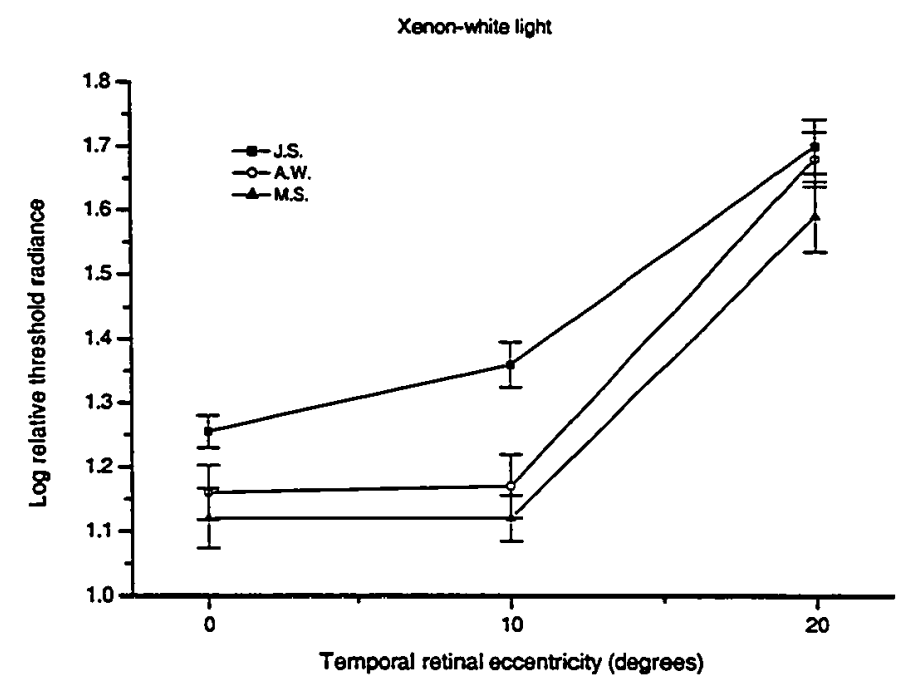

Figure 16: Log relative radiance thresholds for photophobia to xenon-white light, plotted as a function of temporal retinal eccentricity. stimulus, the subjects

produced thresholds that were practically identical

to those found in

Experiment I (spatial summation experiment) at the $9.52^{\circ}$ stimulus size, which is not surprising, as these were identical tasks.

Although identical to Experiment I, the central condition task for Experiment III, which took place approximately one month after Experiment I, was performed as an internal check. Surprisingly, at the $10^{\circ}$ retinal eccentricity location, subjects A.W. and M.S. required essentially the same radiance as the central condition to elicit photophobia. This result was not expected, as many previous authors have documented an increase in 
radiance required to elicit visual discomfort with increasing retinal eccentricity (Waters et al., 1995; IES Handbook, 1981). Subject J.S. does show a slight increase, and all subjects show an increase by $20^{\circ}$. At the $20^{\circ}$ location, the subjects' radiance thresholds appear to converge somewhat.

In the orange light condition, the results for the three subjects (Fig. 17) bear considerable similarity. All three subjects' radiance thresholds ascend nearly linearly as a function of retinai eccentricity. Additionally, the slopes of the three functions are practically identical. The results from these conditions agree in principal with previous findings regarding visual discomfort and retinal

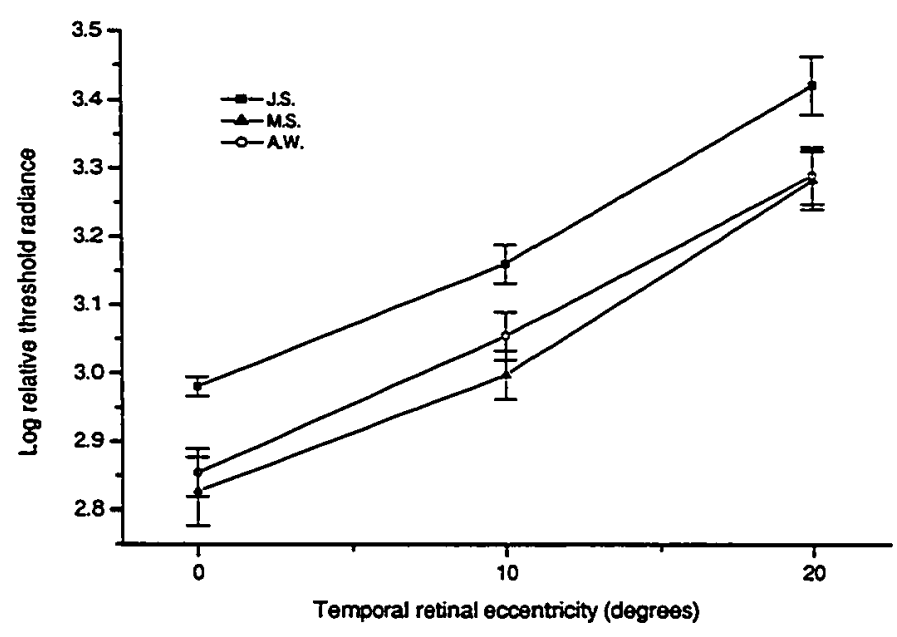
eccentricity (Waters et al., 1995; IES Figure 17: Log relative radiance thresholds for photophobia to orange light, plotted as a function of temporal retinal eccentricity.

Handbook, 1981). The central-viewing condition once again yielded results that very closely approximated the results from the identical condition in Experiment I. Again, subject J.S. was able to tolerate more light than subjects A.W. and M.S. at each eccentricity. This finding is in line with the results from both Experiments I and II, in which subject J.S. was able to tolerate more orange light relative to subjects A.W. and M.S. 


\section{Experiment IV (Photophobia and macular pigment)}

Subjects' individual spatial

distributions of MPOD (averaged

from two sessions), along

horizontal and vertical meridia, are

plotted in Figures 18-20. To enable

visuaiization of the subjects'

complete MPOD distributions, the

data were fit with a Lorentzian

function, which fits the actual

obtained data well, and makes

reasonable estimates of the

distribution peak. The parameters

of the Lorentzian distribution are

similar to those of a Gaussian

distribution. The Lorentizian

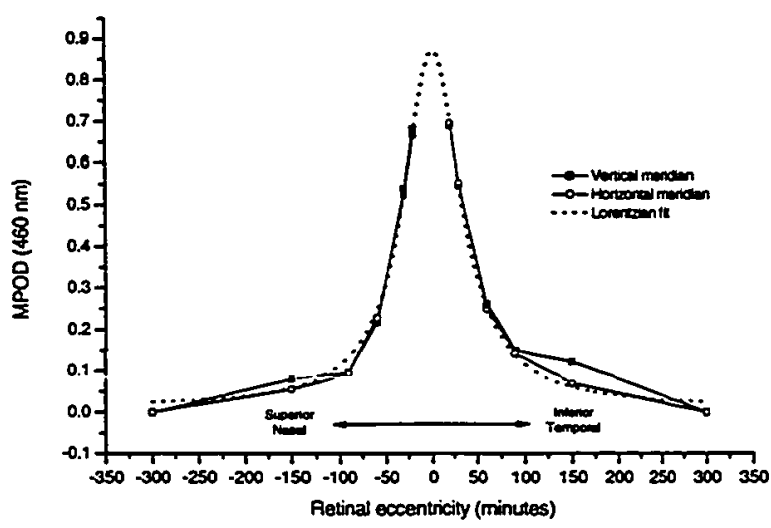

Subject M.S.

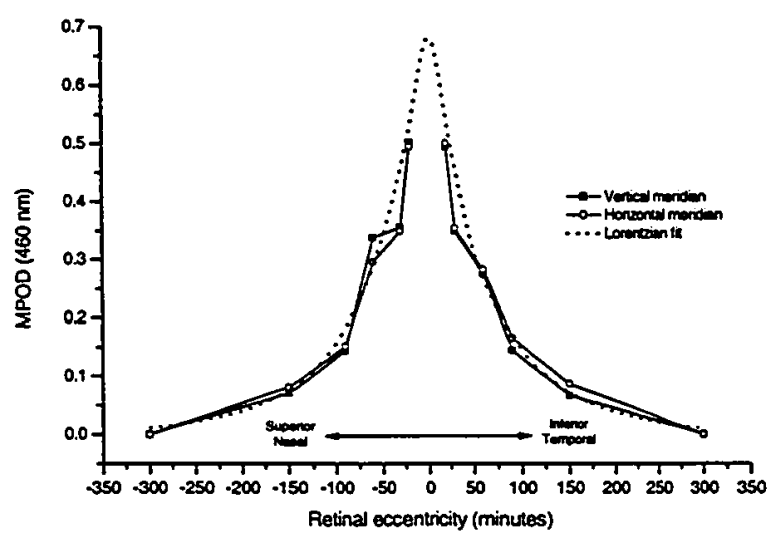

Subject J.S.

distribution is described by the

following equation:

$$
y=y_{0}+\frac{2 \cdot A}{\pi} \cdot \frac{w}{4\left(x-x_{0}\right)^{2}+w^{2}}
$$

where $y_{0}=$ baseline offset; $A=$

total area under the curve from the

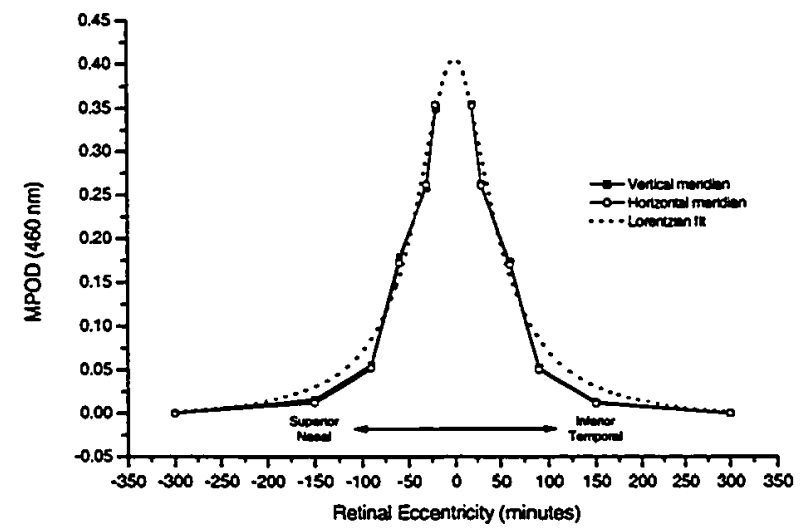

Figures 18-20 (top to bottom): Horizontal and vertical meridian spatial profiles of MPOD at $460 \mathrm{~nm}$ for subjects A.W., M.S., and baseline; $\mathrm{x}_{0}=$ center of the peak; and $\mathrm{w}=$ J.S. Lorentzian functions fit to data and plotted for comparison. 
full width of the peak at half height. A comparison of the Lorentzian fits of the MPOD distribution data are presented in Figure 21. The smallest four stimulus sizes from Experiment I (spatial summation experiment) are plotted at the top of the graph to give

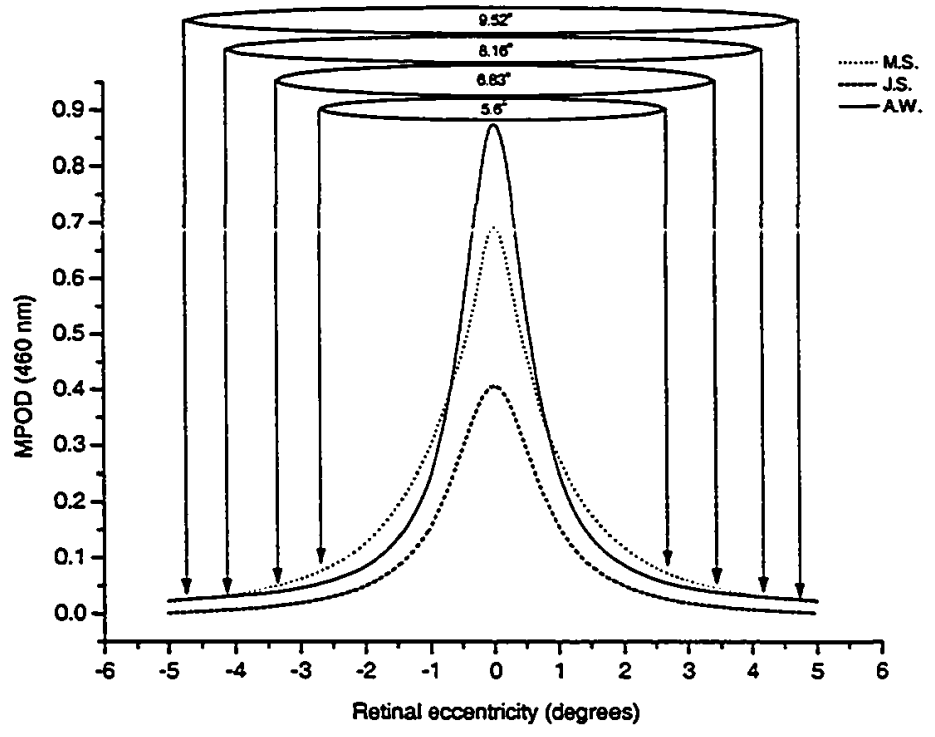

Figure 21: Lorentzian fits to spatial profiles of MPOD for the three subjects. the reader a conception of the relationship between stimulus size and MPOD spatiai distribution. Subject A.W. was found to have the highest peak, followed by subjects M.S. and J.S. Subject M.S.'s MPOD

distribution, although not as leptokurtic as subject A.W.'s, was found to be broader than either A.W.'s or J.S.'s. As expected, the distributions exhibit approximate vertical and bilateral symmetry, with the exception of a broad "shoulder" found in subject M.S.'s superior retina (see Fig. 19). Because this data point appeared aberrant, subject M.S. was tested three times (on three different days) at this retinal eccentricity. On each occasion, she produced the same, unusual shoulder. The shoulder therefore appears to be the result of increased MPOD at this location in the retina, and not an aberration. The MPOD distribution for subject A.W. exhibits a more traditional form, with decreasing (approximately exponential) slopes. Subject J.S.'s MPOD distribution exhibits mild 
shoulders near 90 minutes retinal eccentricity in all quadrants, and features striking vertical and bilateral symmetry.

From Figure 21, it can be seen that subject M.S.'s MPOD distribution is broader than that of either subject J.S. or A.W. This finding is consistent with recently obtained data from Delori (personal communication), who found female subjects' MPOD distributions to be consistently broader than male MPOD distributions. 


\section{CHAPTER VIII}

\section{DISCUSSION}

Photophobia, spatial summation, and macular pigment

The primary finding of these experiments is that photophobia exhibits spatial summation for centraily-viewed stimuï. For both the xenon-white and orange stimuii, summation for photophobia appears roughly to approximate Piper's law, and agrees in this respect with threshold data from Bouman and van der Velden (1947), and Pirenne and O'Doherty (1957). The intriguing aspect of this finding is that the area vs. radiance functions for xenon-white and orange light, respectively, are somewhat different. The function for the orange light condition was found to be linear (see Fig. 13), whereas the xenon-white function appears to contain two (or perhaps, three) "branches" of summation (see Fig. 11). Stringham et al. (2003) showed that short-wavelength light, when corrected for absorption by MP, more readily elicits photophobia. It could be, therefore, that xenon light (which contains much short-wave energy) interacts with MP to give rise to the different branches of summation found in this function. To support this idea, the following explanation is proposed. The first four data points in Figure $9\left(5.6^{\circ}-9.52^{\circ}\right)$ represent the stimuli most strongly screened by MP (see Fig. 21). As stimuli increase in size, MP should become less and less of a factor in attenuating photophobia, as progressively more and more of the stimulus falls on retinal areas lacking MP. For example, the ratio of MP density units / area for subject A.W. is found to be 2.59 times higher for the $5.6^{\circ}$ stimulus than for the $9.52^{\circ}$ stimulus. Subjects were shown to have 
some variability in MP levels (Fig. 21); this, coupled with the increased variability in data for stimuli most strongly screened by MP, suggests that the variability in the area vs. intensity curves could be accounted for by MP. Support for this can be found by examining the slopes of the first four data points in Figure 9. Subjects A.W. and M.S. display slopes in this region that are very similar (linear fits of -0.85 and -0.82 , respectively), with subject J.S.'s slope somewhat flatter (linear fit of -0.47 ). It is proposed that the steeper siopes of $A . \bar{w}$. and $\bar{M} . S$. are indicative of more heaviiyweighted screening by MP for smaller and smaller stimuli for these subjects. Following this line of reasoning, subject J.S., who was found to have substantially less MP than either A.W. or M.S., displays a shallower slope for the first four points, presumably owing to lower MP weighting.

There is a marked difference in MPOD spatial profile shape between subjects A.W. and M.S. Upon integration of MPOD, however, the values for the two subjects was found to be identical (1.67 $\log$ units at $460 \mathrm{~nm}$-subject J.S.'s integrated MPOD value was found to be $0.97 \log$ units at $460 \mathrm{~nm}$ ). This result, coupled with the roughly equivalent slopes for the first four data points in the area vs. radiance functions found for these two subjects suggests that the spatial summation in photophobia effectively integrates MP's filtering. Moreover, beyond the $9.52^{\circ}$ stimulus, the curves come together and take on a similar shape, which supports the notion that, with relatively large stimulus sizes, MP plays less of a mitigating role in photophobia.

If MP is indeed the source of the steeper slope in the xenon-white-derived functions, then what would a xenon-white area vs. radiance function look like for someone with little or no MP? Figures 22-24 present subjects' area vs. intensity functions compared to 


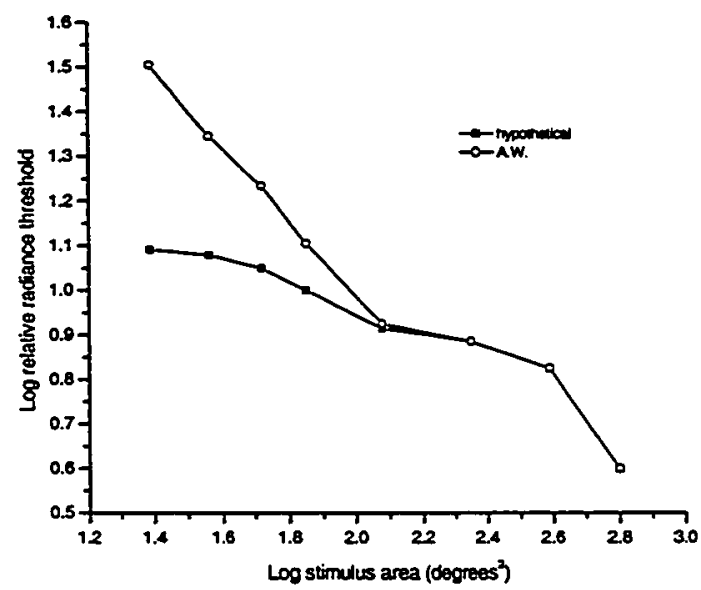

hypothetical, MP-"corrected" functions. These data were obtained by subtracting out the integrated MP effect from the first five points of subjects' xenon-white spatial summation functions. When calculating this effect, careful attention was paid to the spectrai absorption of

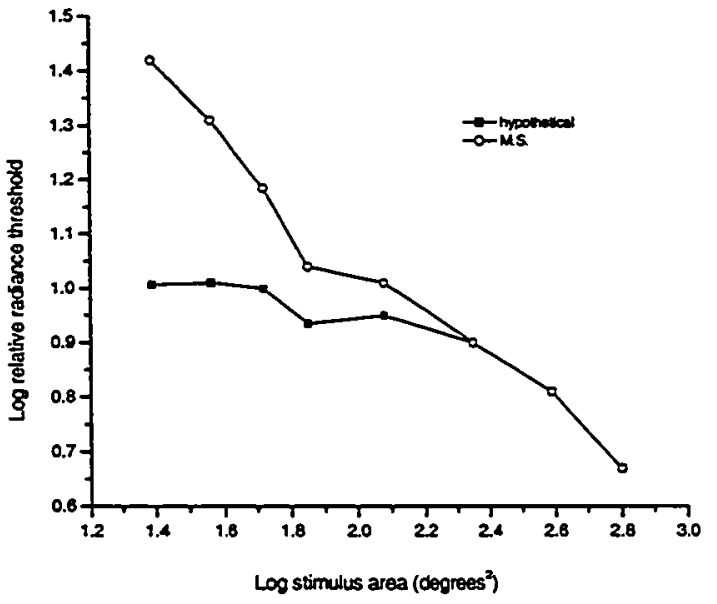

MP, and how it relates to the xenon emission spectrum. Upon inspection of Figures 22-24, we find that the downward slope of radiance thresholds found for the first five points of the actual data flattens out in the hypothetical function, after subtracting

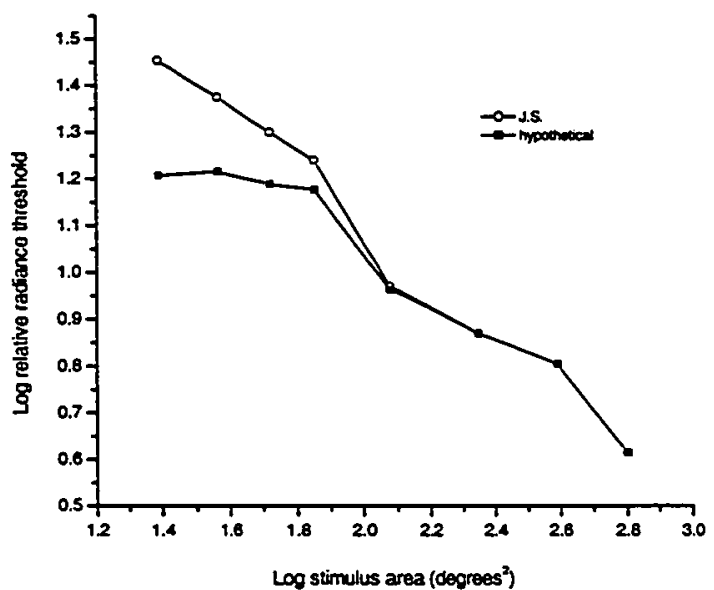
the MP effect. It is important to note here that the hypothetical functions seen in Figures 22-24 are quite different from the orange light functions seen in Figure 12. Both of these functions assume no effect of MP, yet the orange function Figures 22-24 (top to bottom): Xenon-white area vs. intensity plots for subjects A.W., M.S., and J.S. compared to hypothetical MP-corrected functions. effect, whereas the hypothetical xenon- 
white function is "compressed" with decreasing stimulus area. It appears therefore that the introduction of short-wavelength light decreases spatial summation for photophobia.

Perhaps more convincing evidence that MP strongly attenuates photophobia is found in the results for Experiment III (photophobia and retinal eccentricity). For the orange light (which spectrally avoids MP absorption), all three subjects required, in a linear fashion, greater energy to elicit photophobia as retinal eccentricity increased (see Fig. 17). By contrast, the xenon-white light (partiaily screened by $\overline{M P}$ ) produced functions dramatically different from the orange condition, especially for subjects A.W. and M.S. (see Fig. 16). For subjects A.W. and M.S., essentially the same radiance level was required to induce photophobia for central viewing as for the $10^{\circ}$ peripheral viewing condition. Compared to subjects A.W. and M.S., subject J.S. needed less light for central viewing relative to the $10^{\circ}$ condition to elicit photophobia, but still, like the other subjects, his xenon-white function was quite different from his orange function. As with the results from Experiment I (spatial summation experiment), it is proposed that the difference between the xenon-white and orange functions is due to the filtering effects of MP. For the central viewing condition, the $10^{\circ}$ xenon stimulus was filtered by MP, whereas for the $10^{\circ}$ eccentric viewing condition, the stimulus was imaged beyond the spatial extent of MP. For this reason, subjects A.W. and M.S., who were shown to have considerably more MP than subject J.S., were able to tolerate substantially more xenon light in the central viewing condition than what would be dictated by a linear function. As a result of their MP levels, both A.W. and M.S. are shown to be equally sensitive to the xenon stimulus viewed $10^{\circ}$ peripherally as viewed centrally. To a lesser extent (presumably due to less MP), subject J.S. was not able to tolerate as much light in the 
central viewing condition, relative to $10^{\circ}$ viewing, as subjects A.W. and M.S. The hypothesis that MP acts as a spatially-integrated filter for photophobia is supported by these findings-subjects M.S. and A.W. had identical central $/ 10^{\circ}$ peripheral radiance ratios, yet quite different MPOD spatial profiles. As noted above, the two subjects have identical spatially-integrated MP levels, and this presumably accounts for the identical radiance ratios. It should be noted that a curious discrepancy is apparent for subject J.S. with regard to the results presented in Figures 14 and 16. J.S. was able to tolerate more xenon energy relative to the other subjects in Experiment III (see Fig. 16) at all eccentricities tested. In Experiment II (see Fig. 14), however, J.S.'s photophobia thresholds were lower for all quadrants in the immediate parafovea, compared to the other subjects. This discrepancy is difficult to reconcile. Perhaps a more detailed spatial profile of photophobia sensitivity for stimuli of equal size would reveal more interindividual differences.

As mentioned in the results section, the finding that centrally- and peripherally-viewed stimuli of similar light level produce photophobia is surprising, given previous findings of reduced sensitivity with increasing retinal eccentricity (e.g. Waters et al., 1995; IES Handbook, 1981). Given this result, a person with a large amount of MP may find lights in the periphery to be more disturbing, relative to when viewed straight on.

The area vs. radiance functions derived from the orange light stimuli are approximately linear and exhibit considerably less variability in shape among subjects, especially for the four smallest stimuli, than the xenon-white-derived functions (see Fig. 12). Spatial summation for photophobia, thus, appears to depend on the spectral content of the stimulus. Indeed, threshold data from Brindley (1954a) and Volbrecht et al. (2001) 
show that spatial summation is dependent on wavelength. Both of these studies demonstrated that spatial summation for short-wavelength stimuli was greater than that for long-wavelength stimuli. In the case of photophobia, the present data suggest that less spatial summation will be found as the short-wavelength component of a light becomes stronger, particularly in cases of subjects with little or no MP. This kind of pattern may be due to increased photophobia sensitivity to short-wavelength light (when unscreened by $\mathbf{M} \overline{\mathrm{IP}}$ ), as was found by Stringinam et ai. (2003).

Given the results of Stringham et al. (2003), the hypothesized area vs. radiance function for xenon-white light, and the results of Experiment III, it appears that the photophobia response is preferentially biased to prevent the central retina from exposure to potentially damaging short-wavelength light. In this regard, MP appears to act as a spatially-integrated filter, serving to mitigate photophobia to a great extent.

\section{A visual pathway for photophobia}

There has been much speculation on the neurophysiological basis of photophobia. As mentioned in the introduction, the most widely accepted explanation involves vasodilation accompanying the trigemino-pupillary reflex. Unfortunately, however, studies of visual discomfort and pupil response have been inconclusive. Moreover, the finding of binocular summation for visual discomfort (Wirtschafter and Bourassa, 1966; Vanagaite et al., 1997; Vanagaite and Stover, 1998) contradicts the suggestion of the pupil response as a photophobia mechanism, given the well-known consensual light reflex. In other words, for monocular viewing of a photophobia-inducing stimulus, both pupils constrict approximately equally, yet more light is needed to elicit photophobia than 
for binocular viewing.

Photophobia,

therefore, appears to

have a strong central

nervous system

component.

The present study

provides data that are

suggestive of the

pathway that gives rise

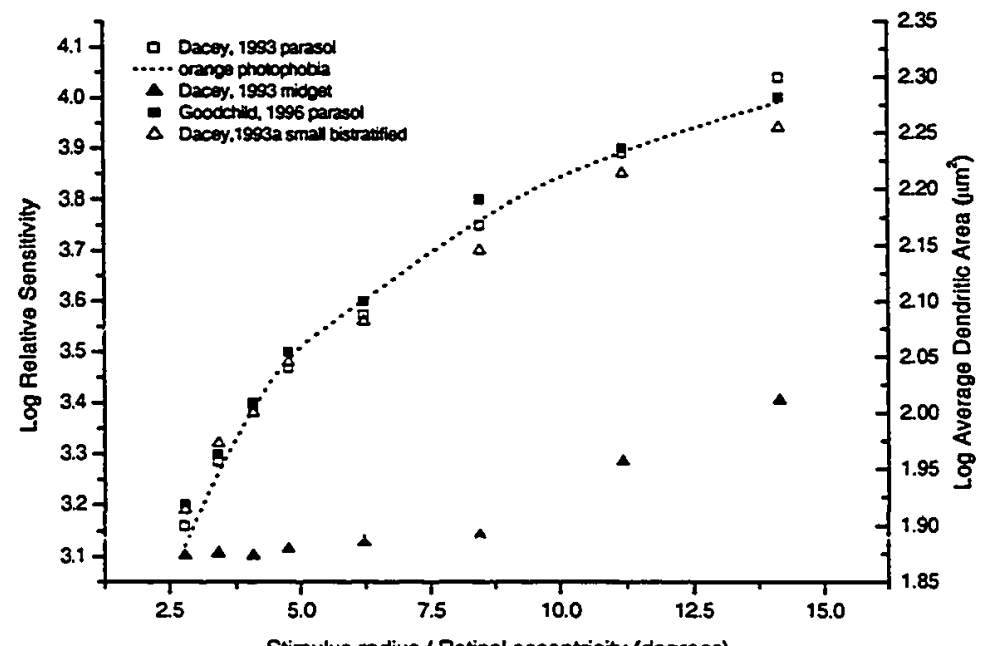

Figure 25: Log relative sensitivity ( 1 / radiance) for photophobia to orange light plotted as a function of stimulus radius. Logarithm of average midget (Goodchild et al., 1996), parasol (Dacey, 1993; Goodchild et al., 1996), and small bistratified (Dacey, 1993a) ganglion cell dendritic field areas plotted for comparison. Photophobia function leastsquares fit to parasol and small bistratified data.

to the photophobia response. When the inverse of the area vs. radiance function

(sensitivity) for the orange light condition is plotted against parasol and small bistratified ganglion cell dendritic areas ${ }^{3}$, the relationships are found to be strikingly similar (Fig.

25). This correspondence suggests that spatial summation for photophobia is

proportional to the dendritic field areas of parasol and small bistratified ganglion cells.

For this plot, the dendritic areas of parasol (using data from Dacey, 1993 and Goodchild et al., 1996) and small bistratified ganglion cells (Dacey, 1993a) contained within the respective areas of the test stimuli were simply averaged. Note that the data are plotted as a function of stimulus radius, in degrees, which was done because the ganglion cell data from both Dacey studies $(1993,1994)$ and Goodchild et al. (1996) are presented as a function of retinal eccentricity. This plot assumes that ganglion cell areas are radially symmetric about the fovea. This is true of superior, temporal, and inferior retina,

\footnotetext{
${ }^{3}$ Ganglion cell dendritic field area closely corresponds to receptive field center area (Lee, 1996).
} 
whereas the nasal retina's ganglion cell dendritic areas, at corresponding eccentricities, are found to be slightly smaller (Watanabe and Rodieck, 1989; Dacey, 1993). The data derived from the orange light condition were chosen to compare to ganglion cell dendritic area, as the former appear to be less affected by complicating factors such as MP. The dendritic areas of midget ganglion cells are plotted for comparison and are found to be quite different from the photophobia, parasol dendritic area, and small bistratified dendritic area piots. The close correspondence of parasol and smail bistratified ganglion cell dendritic areas to photophobia spatial summation suggests that photophobia is mediated via parasol and small bistratified ganglion cells. Despite the very good fit to the orange light-derived area vs. radiance data, the areas of parasol and small bistratified ganglion cell dendritic fields may not tell the complete story. In Experiment III, which assessed photophobia as a function of retinal eccentricity (see Fig. 17), it was found that the threshold for photophobia increased with eccentricity. It could be that the spatial density of ganglion cells or photoreceptors is related to the changes in photophobia sensitivity with eccentricity. To examine this possibility, the average spatial densities of cone photoreceptors (data from Curcio et al., 1990), midget ganglion cells (data from Dacey, 1993), parasol ganglion cells (data from Dacey, 1994), and small bistratified ganglion cells (data from Dacey, 1994) were plotted for regions corresponding to the eccentricity data derived from photophobia to orange light (Fig. 26). From Figure 26 it can be seen that the spatial densities for all cells decrease with eccentricity. The parasol and small bistratified ganglion cell spatial densities, however, appear to decrease in a fashion commensurate with the averaged orange photophobia sensitivity function. This 


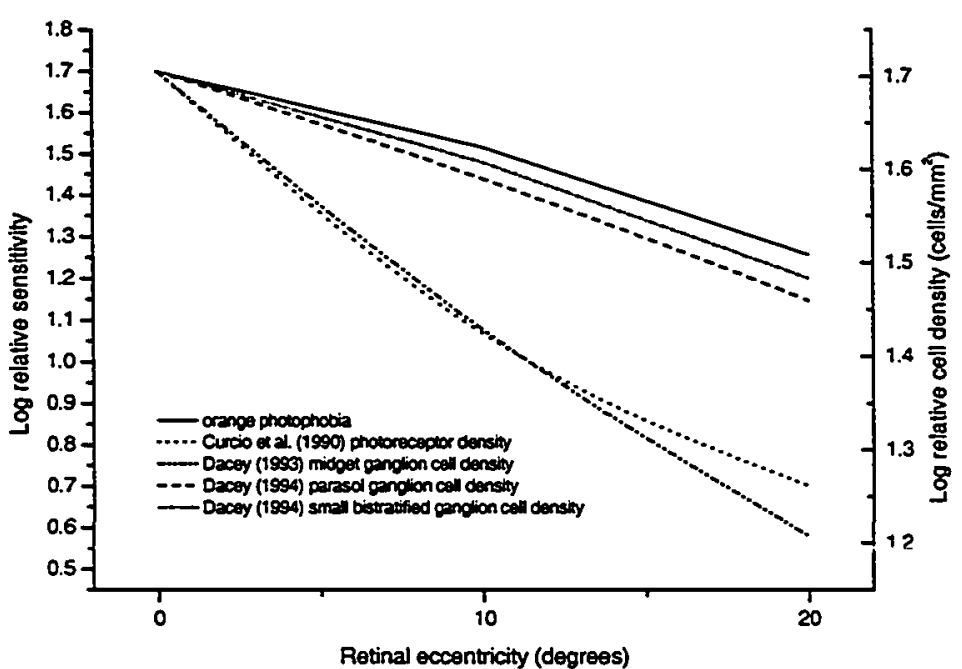

Figure 26: Averaged log relative radiance thresholds for photophobia to orange light, plotted as a function of temporal retinal eccentricity, compared to log relative photoreceptor spatial density (Curcio et al., 1990), midget ganglion cell spatial density (Dacey, 1993), parasol ganglion cell spatial density (Dacey, 1994), and small bistratified ganglion cell spatial density (Dacey, 1994). All functions normalized to the peak sensitivity value for photophobia. finding supports further

the hypothesis that

photophobia is

mediated via parasol

and small bistratified

ganglion cells.

in the centrai retina, parasol ganglion cells

receive input (via bi-

polar cells) from $40-140$

cones, and exhibit relatively large, dense dendritic fields, (Watanabe and Rodieck, 1989;

Dacey, 1993; Goodchild et al., 1996). The overwhelming majority of parasol ganglion cell axons project to layers 1 and 2 of the LGN and terminate in layer $4 \mathrm{C}_{\alpha}$ of $\mathrm{VI}$ (Boycott and Dowling, 1969; Watanabe and Rodieck, 1989). A tiny fraction of parasol ganglion cells appear to project to the pretectum, a structure known to play a role in modulating pupil size in response to changes in illumination (Rodieck, 1998).

Small bistratified ganglion cells, as their name suggests, exhibit dendrites that stratify at two different levels in the inner plexiform layer. They project to koniocellular sublayers $\mathrm{K}_{3}$ or $\mathrm{K}_{4}$ of the parvocellular region of the LGN; relay cells from the LGN serving this pathway terminate in a subset of the blobs (important for color vision-see Hubel, 1995). It was found by Dacey and Lee (1994) that small bistratified ganglion cells are the morphological substrate of the "blue-on, yellow-off" cell. Indeed, the inner "on" arbor of the small bistratified cell receives input from about three S-cone bipolar 
cells, whereas the outer "off" arbor receives input from one of two types of diffuse bipolar cell, which receive from a mixture of approximately twenty M- and L-cones.

In contrast to parasol and small bistratified ganglion cells, midget ganglion cells in the central retina are relatively small, and, in the fovea, receive input from only one cone (Polyak, 1941; Goodchild et al., 1996). Midget ganglion cell axons project to layers 3-6 of the LGN and terminate in layer $4 C_{\beta}$ of V1 (Watanabe and Rodieck, 1989). In contrast to small bistratified cells, midget cells show opponent responses sensitive to only mid and long wavelengths.

The two primary and best understood parallel visual pathways (referred to as parvoand magnocellular) remain segregated until late stages of cortical processing (Hubel, 1995). It has been well established that midget ganglion cells serve the parvocellular visual stream, whereas parasol ganglion cells serve the magnocellular visual stream (Blasdel and Lund, 1983; Rodieck, 1988). Further, detailed experiments by Livingstone and Hubel (1988), and Croner and Kaplan (1994), among others, have characterized specific functions of these two visual pathways. Generally, the parvocellular pathway has been shown to be concerned with color (middle to long wavelengths), texture, and fine patterns, whereas the magnocellular pathway is involved with luminance, motion, and large patterns. Magnocellular cells were shown by Kaplan and Shapley (1986) to be exquisitely sensitive to small changes in luminance and luminance contrast. Moreover, magnocellular cells were shown by Croner and Kaplan (1994) to respond much more vigorously to changes in contrast (greater contrast gain) than their parvocellular counterparts. Certainly these functional specialties are consistent with a mechanism that could give rise to photophobia, and lend support for the idea that photophobia is mediated 
by the magnocellular pathway. The role of the small bistratified ganglion cell in the photophobia "equation" could be one of spectral sensitivity. The relatively high photophobia sensitivity to short-wavelength light could be explained by the small bistratified cell's "blue-on" configuration. Perhaps the parasol and small bistratified ganglion cells act additively to signal visual discomfort. It follows that, as more short wavelength light is introduced, photophobia would be more readily induced. Moreover, the hypothesized MîP-corrected area vs. radiance functions (Figs. 22-24) derived via xenon-white light could be explained by a non-linear additivity (i.e., greater input derived from the small bistratified ganglion cells, relative to parasol ganglion cells).

The hypothesis above does not take into account a role for the rod photoreceptors in producing photophobia. There is, however, some evidence that indicates that rods may contribute to visual discomfort. That the rods are often the primary functioning photoreceptor at the onset of photophobia could suggest a rod-mediated mechanism. Additionally, in the special case of rod monochromats (individuals lacking cones), it is well documented that photophobia is experienced under moderate lighting conditions.

\section{Adaptation level and photophobia}

As noted in the introduction, photophobia is strongly modulated by adaptation level. In other words, the experience of photophobia is achieved with less light in a darkadapted state relative to a light-adapted state. This effect suggests that there exists a "comfortable bandwidth" of visual operation. The general idea of operational range has been studied electrophysiologically in different visual cells of the rhesus monkey. At various adaptation levels, Norman \& Werblin (1974) found the operational range for rod and cone photoreceptors to be 2 to 3 log units of intensity. For cells of the LGN, Jacobs 
(1965) found, regardless of adaptation level, an operational range of approximately 3 to 4 log units. At a strictly dark-adapted level, Barlow, Snodderly and Swadlow (1978) determined the operational range for excitatory LGN cells to be at least $5 \log$ units of intensity. In the same study, Barlow et al. (1978) found that the optic nerve fibers serving the pupil reflex could effectively signal intensity gradations over at least an 8 logunit range. At the cortical level, Bartlett and Doty (1974) found that visual units corresponding to the fovea had operationai ranges of 3 to 4 iog units.

To induce photophobia, there may be necessary a constant intensity increase, relative to adaptation level (up to a certain high adaptation level, of course, where photophobia would be experienced at intensities below the intensity increases necessary at lower adaptation levels). Strictly speaking, the idea that photophobia is strongly modulated by adaptation level refutes the notion that photophobia serves the function of biological protection. It could be that photophobia exists to preserve the dynamic range of visual cells noted above. In the present study, however, subjects required an intensity increase, relative to mesopic-level adaptation, of greater than $8 \log$ units to induce photophobia. The electrophysiologically-determined dynamic ranges for photoreceptors, cells of the LGN, and cortical visual cells are considerably less than the apparent change in light level necessary to induce photophobia. The operational range finding for the pupil response of Barlow et al. (1978) suggests that photophobia may be related to the saturation of the pupil response. Unfortunately, as noted previously, there is no solid evidence relating visual discomfort and pupil response. The author of the present study intends to pursue this point in a future study. 


\section{CHAPTER IX}

\section{CONCLUSIONS}

For centrally-viewed stimuli, photophobia exhibits some spatial summation for targets subtending approximately $5^{\circ}$ to $29^{\circ}$ of visual angle. The degree of spatial summation (slope of -0.61 ) for photophobia to the long-wavelength orange light is somewhat higher than that dictated by Piper's law (slope of -0.50 ), but is nevertheless similar to findings by Bouman and van der Velden (1947) and Pirenne and O'Doherty (1957), who showed Piper's law to hold for large stimuli at absolute threshold. The xenon-white summation functions are more complicated, with two or perhaps three different branches. It is hypothesized that these branches are the result of the filtering effects of MP. Indeed, the results of Experiments I (spatial summation experiment) and III (photophobia and retinal eccentricity) suggest that photophobia is greatly attenuated by MP, which acts as a spatially-integrated short-wavelength filter for the central retina in this regard. Moreover, these results are consistent with and support the original hypothesis of Stringham et al. (2003), who first suggested that MP appears to strongly mitigate photophobia for centrally-viewed stimuli.

The excellent fit of the orange light-derived data to parasol and small bistratified ganglion cell dendritic areas and spatial densities suggests that photophobia is mediated via a combination of the magnocellular and koniocellular visual pathways. With respect

to the magnocellular component, findings by Kaplan and Shapley (1986) and Croner and Kaplan (1994) of high contrast gain and high sensitivity to luminance contrast in 
magnocellular cells further support this hypothesis. The small bistratified ganglion cell component may serve to signal increased short-wavelength input to the photophobia response, and could explain the increased sensitivity to short wavelengths found in the action spectrum for photophobia. Additionally, the differences in photophobia responses to orange and xenon-white light found in the present study could be explained by a nonlinear additivity of parasol and small bistratified ganglion cells.

To determine the respective roies of parasoi and smaili bistratified gangiion ceiis in signaling photophobia, more detailed study of wavelength and spatial interaction is necessary. The present data suggest that less spatial summation will be found as the short-wavelength component of a light becomes stronger, particularly in cases of subjects with little or no MP. As suggested above, this kind of pattern may be due to increased short-wavelength signaling by small bistratified ganglion cells. The increased shortwavelength signaling would presumably manifest as greater photophobia sensitivity to short-wavelength light, consistent with the result found by Stringham et al. (2003). In any case, the results of the present study support and extend the hypothesis that the photophobia response is preferentially biased to prevent the central retina from exposure to potentially damaging short-wavelength light. Photophobia and MP therefore appear to serve a "tandem" function of foveal photoprotection.

Finally, the subjects' overall similarity in photophobia radiance thresholds was striking and unexpected, given the many anecdotal and published reports of vast between-subject differences. Why were the data for the three subjects so similar? There are a few possibilities to consider. First, the similarity found could simply be the result of using three similar subjects. All three are relatively young and healthy. Second, it could 
be that the methods used for this study afforded a high level of experimental control, which translated into low between-subject variability. With respect to experimental control, the high between-subject variability found by many authors (e.g., Wirtschafter and Bourassa, 1966; Berman et al., 1996) could be due to poor control of adaptation level. Third, previous studies of visual discomfort have almost exclusively employed subjective rating scales, which may have resulted in high variability among subjects. The method (EMG) used for assessing photophobia, coupled with the procedure empioyed in the present study appears to produce consistent, reliable data. 


\section{REFERENCES}

Abney, D.S. (1897). The sensitiveness of the retina to light and colour. Philosophical Transactions of the Royal Society, London, A. 190A, 155-193.

Aulhom, E., Harms, H. (1972). Visual perimetry. In Handbook of Sensory Physiology, V. 4: Visual Psychophysics. Jameson and Hurvich (eds.). Pp. 102-145. Springer-Verlag: Berlin, Heidelberg, New York, 1972.

Banks, M.S., Geisler, W.S., Bennett, P.J. (1987). The physical limits of grating visibility. Vision Research. 27, 1915-1924.

Barlow, H.B. (1953). Summation and inhibition in the frog's retina. Journal of Physiology. 69, 8-17.

Barlow, R.B., Snodderly, D.M., Swadlow, H.A. (1978). Intensity coding in primate visual system. Experimental Brain Research. 31: 163-177.

Bartlett, J.R., Doty, R.W. (1974). Response of units in striate cortex of squirrel monkeys to visual and electrical stimuli. Joumal of Neurophysiology. 37: 621-641.

Baumgardt, B.L. (1947). The quantic and statistical basis of visual excitation. Journal of Physiology. 31, 268.

Baumgardt, B.L. (1949). Les theories photochimiques classiques et quantiques de la vision et l'inhibition nerveuse en vision luminaire. Revue Opt. 28, partie theorique 453479; partie experimentale 661-690. As cited in Visual Psychophysics, 1972, Jameson and Hurvich (eds).

Baumgardt, E., Hillmann, B. (1961). Duration and size as determinants of peripheral retinal response. Journal of the Optical Society of America. 51, 340-344.

Berman, S., Bullimore, M., Jacobs, R., Bailey, I., Gandhi, N. (1994). An objective measure of discomfort glare. Journal of the Illuminating Engineering Society. Summer: $40-48$

Blasdel, G.G., Lund, J.S. (1983). Termination of afferent axons in macaque striate cortex. Journal of Neuroscience. 3: 1389-1413.

Bone, R. A., Landrum, J. T., Fernandez, L., Tarsis, S. L. (1988). Analysis of the macular pigment by HPLC: Retinal distribution and age study. Investigative Ophthalmology and Visual Science, 29, 843-849.

Bone, R. A., Landrum, J. T., Cains, A. (1992). Optical density spectra of the macular pigment in vivo and in vitro. Vision Research, 32, 105-110. 
Bouman, M.A., van der Velden, H.A. (1947). The two-quanta explanation of the dependence of the threhsold values and visual acuity on the visual angle and the time of observation. Journal of the Optical Society of America. 37 (11): 908-919.

Boycott, B.B., Dowling, J.E. (1969). Organization of the primate retina: Light microscopy. Philosophical Transactions of the Royal Society, London B. 255, 109-184.

Brindley, G.S. (1954a). The summation areas of human colour-receptive mechanisms at increment threshold. Journal of Physiology. 122, 332-350.

Campbell, F.W., Gubisch, R.W. (1966). Optical quality of the human eye. Journal of Physioiogy Lonaion. i86: 558-578.

Chen, S.F., Chang, Y., Wu, J.C. (2001). The spatial distribution of macular pigment in humans. Current Eye Research. 23 (6): 422-434.

Chronicle, E. P., Mulleners, W. M. (1996). Visual system dysfunction in migraine: A review of clinical and psychophysical findings. Cephalalgia, 16, 525-535.

Cicerone, C.M., Nerger, J.L. (1989). The relative numbers of long-wavelength-sensitive to middle-wavelength-sensitive cones in the human fovea centralis. Vision Research, 29, 115-128.

Coleston, D.M., Chronicle, E., Ruddock, K.H., Kennard, C. (1994). Precortical dysfunction of spatial and temporal visual processing in migraine. Journal of Neurology, Neurosurgery, and Psychiatry, 57, 1208-1211.

Cornsweet, T.N. (1956). Determination of the stimuli for involuntary drifts and saccadic eye movements. Journal of the Optical Society of America, 46, 987-998.

Croner, L.J., Kaplan, E. (1994). Receptive fields of P and M ganglion cells across the primate retina. Vision Research. 35 (1): 7-24.

Curcio, C.A. (1987). Diameters of presumed cone apertures in human retina. Journal of the Optical Society of America, A. 4, 70.

Curcio, C.A., Sloan, K.R., Kalina, R.E. (1990). Human photoreceptor topography. Journal of Comparative Neurology. 292: 497-523.

Curcio, C.A., Allen, K.A., Sloan, K.R., Lerea, C.L., Hurley, J.B., Klock, I.B., Milam, A.H. (1991). Distribution and morphology of human cone photoreceptors stained with anti-blue opsin. Journal of Comparative Neurology, 312, 610-624. 
Curran-Celentano, J., Hammond, B.R., Ciulla, T.A., Cooper, D.A., Pratt, L.M., Danis, R.B. (2001). Relation between dietary intake, serum concentrations, and retinal concentrations of lutein and zeaxanthin in adults in a midwest population. American Journal of Clinical Nutrition. 74, 796-802.

Dacey, D.M. (1993). The mosaic of midget ganglion cells in the human retina. Journal of Neuroscience. 13: 5334-5355.

Dacey, D.M., Lee, B.B. (1994). The blue-ON opponent pathway in primate retina originates from a distinct bistratified ganglion cell type. Nature. 367: 731-735.

Dacey, D.M. (1994). Morphology of a small-field bistratified ganglion cell type in the macaque and numan retina. Visuai iveuroscience. iô (ó): i0

Dacey, D.M. (1994). Physiology, morphology and spatial densities of identified ganglion cell types in primate retina. In Goode, J. and Morgan, M. (Eds.), Higher order processes in the visual system (pp. 12-34). Chichester: Wiley.

Davila, K.D., Geisler, W.S. (1991). The relative contributions of pre-neural and neural factors to areal summation in the fovea. Vision Research. 31, 1369-1380.

de Boer, J. B. (1967). Visual perception in road traffic and the field of vision of the motorist. Public Lighting. Eindhoven, The Netherlands: Phillips Technical Library. 11 96.

Drummond, P. (1986). A quantitative assessment of photophobia in migraine and tension headache. Headache. 26: 465-9.

Drummond, P., Woodhouse, A. (1993). Painful stimulation of the forehead increases photophobia in migraine sufferers. Cephalalgia, 13: 321-324.

Drummond, P. (1997). Photophobia and autonomic responses to facial pain in migraine. Brain. 120: 1857-1864.

Eckhardt, B., McClean, J.M., Goodell, H. (1943). Experimental studies on headache: The genesis of pain from the eye. Joumal of Nerves and Mental Disorders. 23: 209-27.

Enroth-Cugell, C., Robson, J.G. (1966). The contrast sensitivity of retinal ganglion cells of the cat. Journal of Physiology, London. 187: 517-552.

Fischer, B. (1973). Overlap of receptive field centers and representation of the visual field in the cat's optic tract. Vision Research. 13: 2113-2120.

Fischer, B., May, H.U. (1970). Invariances in the cat's retina: Principles in the relations between sensitivity, size and position of receptive fields of ganglioin cells. Experimental Brain Research. 11: 448-464. 
Glezer, V.D. (1965). The receptive fields of the retina. Vision Research. 5: 497-525.

Goodchild, A.K., Ghosh, K.K., Martin, P.R. (1996). Comparison of photoreceptor spatial density and ganglion cell morphology in the retina of human, macaque monkey, cat, and the marmoset callithrix jacchus. Journal of Comparative Neurology. 366: 55-75.

Gorgels, T., van Norren, D. (1995). Ultraviolet and Green Light Cause Different Types of Damage in Rat Retina. Investigative Ophthalmology and Vision Science. 36(5): 851863.

Graham, C.H. (1934). Vision III. Some neural correlations. In C. Murchison (Ed.), Ḧanäbooḱ of generai experimentai psychoiogy. Worcester, ivíass: Ciark Üniversity Press. Pp. 829-879.

Graham, C.H., Brown, R.H., Mote, F.A. (1939). The relation of size of stimulus and intensity in the human eye: I. Intensity thresholds for white light. Journal of Experimental Psychology. 24: 555-573.

Granit, R. (1930). Comparative studies on the peripheral and central retina: I. On interaction between distant areas in the human eye. American Journal of Physiology. 94: 41-50.

Guth, S.L. (1971). On probability summation. Vision Research. 11(7): 747-750.

Hallett, P.E. (1963). Spatial summation. Vision Research. 3: 9-24.

Hallett, P.E., Marriott, F.H.C., Roger, F.C. (1962). The relationship of visual threshold to retinal position and area. Journal of Physiology. 160: 364-373.

Ham, W. T., Mueller, H. A., Sliney, D. H. (1976). Retinal sensitivity to damage from short wavelength light. Nature. 260: 153-155.

Hammond, B. R., Wooten, B. R., Snodderly, D. M. (1997). Individual variations in the spatial profile of macular pigment. Journal of the Optical Society of America (A). 6: 1187-1196.

Hammond, B. R., Wooten, B. R., Snodderly, D. M. (1998). Preservation of visual sensitivity of older subjects: Association with macular pigment density. Investigative Ophthalmology and Vision Science. 36: 1-10.

Handelman, G.J., Dratz, E.A., Reay, C.C., Kuijk, F.J.G.M. (1988). Carotenoids in the human macula and whole retina. Investigative Ophthalmology and Vision Science. 43(1): 47-50. 
Harrington, D.O. (1981). The visual fields: A textbook and atlas of clinical perimetry. $5^{\text {th }}$ ed. C.V. Mosby Company. St. Louis, Toronto, London.

Hartline, H.K., Graham, C.H. (1932). Nerve impulses from single receptors in the eye. Journal of Cellular and Comparative Physiology. 1: 277-295.

Hartline, H.K. (1940). The effects of spatial summation in the retina on the excitation of the fibers in the optic nerve. American Journal of Physiology. 130: 700-711.

Hecht, S., Shlaer, S., Pirenne, M.H. (1942). Energy, quanta, and vision. Jounal of General Physiology. 25: 819-840.

Fieimnoitz, Hi. von. (i 1860 ). Hand̈buch der physioiogischen Optik. (Ĵrd ed.). Hamburg \& Leipzig: Voss, 1909-1911. As cited in Woodworth and Schlosberg's Experimental Psychology, 1971.

Hopkinson, R. (1956). Glare discomfort and pupil diameter. Journal of the Optical Society of America. 46: 649-656

Howarth, P., Heron, G., Greenhouse, D., Bailey, I., Berman, S. (1993). Discomfort from glare: the role of pupillary hippus. Journal of Illumination Engineering. 25: 37-42

Hubel, D.H. (1995). Eye, Brain, and Vision. Scientific American Library. New York.

IES Lighting Handbook, application volume, J. E. Kaufman (Ed) and H. Haynes (Assoc. Ed), IES, New York, 1981. Pp. 43-47.

Inui, T., Mimura, O., Kani, K. (1981). Retinal sensitivity and spatial summation in the foveal and parafoveal regions. Joumal of the Optical Society of America. 71(2): 151154.

Jacobs, G.H., Youlton, R.L. (1970). Center surround balance in receptive fields of cells in the lateral geniculate nucleus. Vision Research. 10: 1127-1144.

Jacobs, G.H. (1965). Effects of adaptation on the lateral geniculate response to light increment and decrement. Journal of the Optical Society of America. 55: 1535-1540.

Jameson, D., Hurvich, L.M. (eds.) (1972). Handbook of Sensory Physiology, V. 4: Visual Psychophysics. Springer-Verlag: Berlin, Heidelberg, New York, 1972.

Kaiser, P.K. (1988). Sensation luminance: A new name to distinguish CIE luminance from luminance dependent on an individual's spectral sensitivity. Vision Research. 28 (3): $455-456$. 
Kaplan, E., Shapley, R.M. (1986). The primate retina contains two types of ganglion cells, with high and low contrast sensitivity. Proceedings of the National Academy of Sciences U.S.A. 83: 2755-2757.

Khachik, F., Beecher, G.R., Goli, M.B., Lusby, W.R. (1992b). Separation and quantification of carotenoids in foods. In: Methods of Enzymology. San Diego: Academic Press, 213A, 347-359.

King, V. (1972). Discomfort glare from flashing sources. Journal of the American Optometric Association. 43: 53-56

Kling, J.W., Riggs, L. A. (1971). Woodworth and Schlosberg's Experimental Psychoiogy. ( $3^{\text {rd }}$ ed.). hroit, Rinehart, and Winston, inc. New York.

Krinsky, N.I., Landrum, J.T., Bone, R.A. (2003). Retinal protection from the macular carotenoids lutein and zeaxanthin. Annual Review of Nutrition. Electronic publication: http://nutr.annualreviews.org/cgi/reprint/011702.073307v3.pdf

Kuffler, S. (1953). Discharge patterns and functional organization of the mammalian retina. Journal of Neurophysiology. 16: 37-68.

Lebensohn, J. E. (1934). The nature of photophobia. Archives of Ophthalmology. 12: 380-390.

Lebensohn, J. E. (1951). Photophobia: Mechanism and implications. American Journal of Ophthalmology. 34: 1294-1300.

Lee, B.B. (1996). Receptive field structure in the primate retina. Vision Research. 36 (5): 631-644.

Levelt, W. (1964). On binocular rivalry. Soesterberg (The Netherlands): Institute for Perception, RVO-TNO, 1964.

Lie, I. (1980). Visual detection and resolution as a function of retinal locus. Vision Research. 20: 967-974.

Livingstone, M.S., Hubel, D.H. (1988). Segregation of form, color, movement, and depth: Anatomy, physiology, and perception. Science. 240: 740-749.

Murray, I., Plainism, S., Carden, D. (2002). The ocular stress monitor: A new device for measuring discomfort glare. Lighting Research. 34 (3): 231-242.

Norman, B., Werblin, J. (1974). Control of retinal sensitivity. I. Light and dark adaptation of vertebrate rods and cones. Journal of General Physiology. 63: 37-61. 
Østerberg, G. (1935). Topography of the layer of rods and cones in the human retina. Acta Ophthalmologica. 6 (suppl): 1-103.

Piper, H. (1903). Uber die Abhangigkeit des Reizwertes leuchtender Objeckte von ihrer Flachenbezw. Winkelgrobe. Z Psych. Physiolo. Sinnesorg. 32, 98-112. As cited in Visual Psychophysics, Jameson and Hurvich (eds.).

Pirenne, M.H., O’Doherty, E.F. (1957). Individual differences in night-vision efficiency. P.R. Spec Rep Ser Med Res Coun. London, 294. As cited in Woodworth and Schlosberg's Experimental Psychology, 1971.

Polyak, S. (1941). The Retina. Chicago, University of Chicago Press.

Ratliff, F. (1962). Some interrelations among physics, physiology, and psychology in the study of vision. In S. Koch (Ed.), Psychology: A study of a science. Vol 4: Biologically oriented fields: Their place in psychology and in biological science. New York: McGraw-Hill. Pp. 417-482.

Ricco, A. (1877). Relazione fra il minim angolo visuale e l'intensita luminosa. Mem. $R$. Acad. Sci. Lett. Arti Modena. 17: 47-160. As cited in Volbrecht, Shrago, Schefrin, and Werner, 2000.

Rodieck, R.W. (1988). The primate retina. In H.D. Steklis and J. Erwin (eds.), Comparative Primate Biology, Vol. 4. New York, Alan R. Liss, Inc. pp. 203-278.

Rodieck, R.W. (1998). The first steps in seeing. Sunderland, Massachusetts. Sinauer Associates, Inc.

Sakitt, B. (1971). Configuration dependence of scotopic spatial summation. Journal of Physiology, London. 216: 513-529.

Samsonova, V.G. (1948). Light sensitivity as a function of intensity, area and localization on the retina. Doctoral Dissertation, Leningrad (Russian).

Schefrin, B.E., Bieber, M.L., McLean, R., Werner, J.S. (1998). The area of complete scotopic spatial summation enlarges with age. Journal of the Optical Society of America. 15 (2): 340-348.

Scholtes, A.M.W., Bouman, M.A. (1976). Psychophysical experiments on spatial summation at threshold level of the human peripheral retina. Vision Research. 17: 867873.

Schultze, M. (1866). Ueber den gelben Fleck der Retina, seinen Einfluss auf normales Sehen und auf Farbenblindheit. Bonn: von Max Cohen \& Sohn. As cited by Werner, Donnelly, \& Kliegl, 1987. 
Siegwart, K. (1920). Zur Frage nach dem Vorkommen und dem Wesen des Blendungsschmerzes. Schweiz. Med. Wchnschr, 50: 1165. As cited by Lebensohn, 1934.

Sliney, David H. (1997). Ocular Exposure to Environmental Light and Ultraviolet-the Impact of Lid Opening and Sky Conditions. Developments in Ophthalmology. 27: 6375.

Snodderly, D.M., Auran, J.D., Delori, F.C. (1984a). The macular pigment II. Spatial distribution in primate retinas. Investigative Ophthalmology and Visual Science. 25: 674-685.

Snodieriy, D.ivi., Brown, F.K., Delori, F.C., Auran, J.D. (1984b). The macular pigment I. Absorbance spectra, localization and discrimination from other yellow pigments in primate retinas. Investigative Ophthalmology and Visual Science. 25: 660-672.

Snodderly, D.M. (1995). Evidence for protection against age-related macular degeneration by carotenoids and antioxidant vitamins. American Journal of Clinical Nutrition. 62 (suppl): 1448S-1461S.

Stone, J. (1965). Quantitative analysis of distribution of ganglion cells in the cat's retina. Journal of Comparative Physiology, London. 124: 337-352.

Stringham, J.M., Fuld, K., Wenzel, A.J. (2003). An action spectrum for photophobia (in press).

Vanagaite, J., Pareja, J.A., Storen, O, White, L.R., Sanc, T., Stovner, L.J. (1997). Lightinduced discomfort and pain in migraine. Cephalalgia. 17: 733-741.

Vanagaite-Vingen, J., Stovner, L.J. (1998). Photophobia and phonophobia in tensiontype and cervicogenic headache. Cephalalgia. 18: 313-318.

Volbrecht, V.J., Shrago, E.E., Schefrin, B.E., Werner, J.S. (2000). Spatial summation in human cone mechanisms from $0^{\circ}$ to $20^{\circ}$ in the superior retina. Journal of the Optical Society of America. 17 (3): 641-650.

Vos, J. J. (1972). Literature review of human macular absorption in the visible and its consequences for the cone receptor primaries. Institute for Perception, RVO-TNO, IZF 1972-17, Soesterberg, The Netherlands.

Wassle, H., Grunert, U., Rohrenbeck, J. Boycott, B.B. (1989). Cortical magnification factor and the ganglion cell density of the primate retina. Nature. 341: 643-646.

Watnabe, M., Rodieck, R.W. (1989). Parasol and midget ganglion cells of the primate retina. Journal of Comparative Neurology. 289: 434-454. 
Waters, C., Mistrick, R., Bernecker, C. (1995). Discomfort glare from sources of nonuniform luminance. Joumal of the Illuminating Engineering Society. Summer. 7383.

Weale, R.A. (1958). Retinal summation and human visual thresholds. Nature, London. 181: 154 .

Werner, J.S., Donnelly, S.K., Kliegl, R. (1987). Aging and human macular pigment density. Vision Research. 27 (2): 257-268.

Wiesel, T.N. (1960). Receptive fields of ganglion cells in the cat's retina. Journal of Physiology, London. 153: 583-594.

Wirtschafter, J.D., Bourassa, C.M. (1966). Binocular facilitation of discomfort with high luminances. Archives of Ophthalmology. 75: 683-8.

Wooten, B.R., Hammond, B.R., Land, R.I., Snodderly, D.M. (1999). A practical method for measuring macular pigment optical density. Investigative Ophthalmology and Visual Science. 40 (11): 2481-2489.

Yates, S. K., Brown, W. F. (1981). Light-stimulus-evoked blink reflex: Methods, normal values, relation to other blink reflexes, and observations in multiple sclerosis. Neurology. 31 (3): $272-81$.

Zuidema, P., Verschuure, H., Bouman, M.A., Koenderink, J.J. (1981). Spatial and temporal summation in the human dark-adapted retina. Journal of the Optical Society of America. 71 (12): 1472-1480. 